IRARRÁZABAL, Paz. "Igualdad en las calles en Chile: el caso del control de identidad".

Polít. crim. Vol. 10, № 19 (Julio 2015), Art. 8, pp. 234-265.

[http://www.politicacriminal.cl/Vol_10/n_19/Vol10N19A8.pdf]

\title{
Igualdad en las calles en Chile: el caso del control de identidad. ${ }^{1}$
}

\section{Equality on the streets in Chile: the case of identity check.}

\author{
Paz Irarrázabal González \\ Ph.D. (c) King's College London. \\ pazira@gmail.com
}

\section{Resumen}

Este artículo argumenta que el control de identidad es una amenaza a la construcción de un espacio público en donde todas las personas sean tratadas con igual respeto. Se sostiene que en sociedades desiguales el ejercicio de facultades policiales preventivas afecta desproporcionadamente a grupos desaventajados, creando o reforzando estereotipos, jerarquías sociales y segregación urbana. Para aseverar lo anterior se revisa la discusión parlamentaria suscitada por la creación de dicha facultad policial así como en sus posteriores reformas. Luego, a partir de denuncias de la ciudadanía y algunos casos penales se analizan algunas pistas de cómo el control de identidad se ha usado en la práctica. A pesar de que cerca de dos millones de controles se efectúan al año este artículo constata una preocupante falta de información acerca de las circunstancias y personas sometidas a dichos procedimientos. Por ello se recurre a la discusión británica con respecto a un poder policial similar, poniendo en evidencia el potencial discriminatorio de la institución.

Palabras clave: Control de identidad, igualdad, espacio público, stop and search.

\begin{abstract}
This article argues that the police power to identity check is a threat to the creation of a public space in which everyone is treated with equal respect. It is claimed that in unequal societies the use of preventive police powers has a disproportionate impact on disadvantaged groups, creating or reinforcing stereotypes, social hierarchies and urban segregation. To support the preceding the parliamentary debates triggered by the creation of this police power and its reforms are reviewed. Then, drawing upon the complaints from the citizenry and the criminal case law, some hints regarding how the identity check has been used in practice are examined. Despite the fact that around two million of checks take place every year, this article reveals a disquieting lack of data regarding the circumstances and people who endure these procedures. Because of this, it uses the British debate concerning a similar police power, exposing the discriminatory potential of the institution under discussion.
\end{abstract}

\footnotetext{
${ }^{1}$ Agradezco los generosos comentarios a este trabajo de Vicente Aliaga, Paula Arrieta, y Guillermo Jiménez.
} 
IRARRÁZABAL, Paz. "Igualdad en las calles en Chile: el caso del control de identidad".

Key words: Identity check, equality, public space, stop and search

\section{Introducción}

Las calles y plazas de la ciudad son lugares de encuentro y diversidad. La libertad y la exposición a nuevas experiencias que son posibles en estos espacios explican la fascinación y placer que generan para muchas personas. Sin embargo, para otras, las calles son (también) lugares de discriminación y opresión. Importantes diferencias en el disfrute de las calles son el resultado de problemas estructurales de injusticia social. En otras palabras, las desventajas que ciertos grupos sufren en distintas esferas sociales se expresan también en los espacios comunes de la ciudad. Así, por ejemplo, personas con dificultades para movilizarse se ven privadas de igual acceso y uso de los espacios públicos por diseños urbanos poco inclusivos; las mujeres son vulneradas por el acoso sexual en las calles; miembros de minorías étnicas y sexuales, inmigrantes y personas de bajos recursos pueden ser víctimas de miradas despectivas, exclusión, comentarios y tratos discriminatorios. De la misma forma, personas pertenecientes a estos grupos son vulnerables a ser objeto de excesiva vigilancia y acoso policial.

En este artículo me enfocaré en una forma específica de interacción en las calles que plantea complejos e invisibles problemas de justicia en Chile, esto es, la interacción entre ciudadanos y Carabineros, a propósito del ejercicio de la facultad para controlar la identidad. Este poder permite a Carabineros parar a una persona en la calle y exigirle evidencia sobre su identidad cuando existan razones para sospechar que se ha cometido una infracción penal o la persona pretende ocultar su identidad. Con el objeto de exponer algunos de los peligros que esta facultad implica para la libertad e igualdad de los ciudadanos, revisaré en este artículo, en primer lugar, algunos antecedentes de su creación y exploraré algunas pistas sobre su uso. En segundo lugar, dada la falta de información y control que existe en Chile acerca del ejercicio efectivo del control de identidad, introduciré la discusión desarrollada en el Reino Unido con respecto a un poder similar de policía: el stop and search. Algunos de los argumentos desarrollados en dicho contexto serán de gran utilidad para entender las amenazas a la justicia en el espacio público que implica el control de identidad en Chile. Argumentos similares se han desarrollado también en otras democracias, sin embargo como explicaré más adelante, hay buenas razones para detenerse en el caso británico.

En la tercera parte concluiré argumentando que en el contexto chileno el control de identidad constituye un serio peligro para los derechos de las personas, especialmente para aquellas que pertenecen a grupos que carecen de poder. Dada la desigualdad social existente en Chile, el control de identidad restringe la libertad de algunos de manera desproporcionada. El costo social que implica el uso de la facultad policial para el supuesto fin de resguardar la seguridad de todos se encuentra distribuido de manera arbitraria. La igualdad se ve afectada también por el inevitable uso de estereotipos cuando lo que se controla, en la práctica, es la apariencia de una persona para decidir sobre su respetabilidad. Criterios usados en las cortes en Chile como indicios que autorizarían el control, tales como 
Polít. crim. Vol. 10, № 19 (Julio 2015), Art. 8, pp. 234-265.

[http://www.politicacriminal.cl/Vol_10/n_19/Vol10N19A8.pdf]

ponerse nervioso frente a Carabineros o estar "fuera de lugar", contribuyen a reforzar estereotipos y jerarquías sociales.

De esta forma este artículo pretende contribuir a una reflexión crítica sobre problemas de justicia social que se suscitan con el uso del control de identidad. La preocupación que guía este trabajo va más allá de la tensión que existe entre poderes policiales preventivos y libertades individuales (aproximación más tradicional en la discusión chilena) sino que atiende especialmente al impacto que estos poderes tienen en grupos desaventajados en sociedades desiguales como la nuestra. En cuanto a su metodología, este trabajo recurre a una aproximación socio-legal que permite examinar críticamente una institución jurídica en su contexto.

\section{Control de identidad en Chile.}

De acuerdo a Guillermo O’Donnell, las fuerzas policiales en Latinoamérica son las instituciones más relevantes en la vida cotidiana de las personas pertenecientes a grupos desaventajados $^{2}$. En particular, las interacciones que los miembros de grupos vulnerables tienen con la policía afectan significativamente su bienestar en los espacios públicos. Una circunstancia que da lugar a estas interacciones en Chile es el ejercicio del control de identidad. En esta primera sección examinaré la historia reciente de la regulación de esta institución en Chile y luego revisaré como ha sido usado en la práctica.

\subsection{El control de identidad y la historia de su regulación.}

El control de identidad es una facultad autónoma de la policía regulada en el artículo 85 del Código Procesal Penal. Este artículo faculta a los funcionarios policiales a solicitar identificación de cualquier persona cuando estimaren que existen indicios de que hubiere cometido o intentado cometer un crimen, simple delito o incluso una falta, de que se dispusiera a cometerlo, o en caso que la persona pueda proveer información sobre estos hechos. También la policía puede solicitar identificación a una persona que se encapuche o emboce para ocultar su identidad. La identificación debe realizarse a través de documentos oficiales. En dicho procedimiento la policía puede registrar la vestimenta, equipaje o vehículo de la persona sujeta a control, así como constatar la existencia de órdenes de detención pendientes.

Si la persona se rehúsa a ser identificado o si no puede proveer identificación alguna, la policía la conducirá a la unidad policial más cercana. Si aun en ese lugar la persona se niega a identificarse o la policía tiene indicios para creer que ha ocultado su verdadera identidad, la persona puede ser detenida debiendo ser presentada ante un juez en un plazo máximo de 24 horas. La policía a cargo del ejercicio de este poder es Carabineros y la Policía de Investigaciones de Chile. Este artículo se centrará en la labor de la primera institución señalada dada su mayor presencia en las calles, que es el foco de este trabajo.

\footnotetext{
${ }^{2}$ O'DONNELL, Guillermo, Democracy, Agency, and the State: Theory with Comparative Intent, Oxford: Oxford University Press, 2010, p. 152.
} 
La facultad policial de control de identidad fue creada en 1998 por la Ley 19.567 como una medida entre otras para el fortalecimiento del sistema democrático. Su dictación fue el resultado de una negociación parlamentaria donde se buscaba eliminar las ofensas de vagancia y mendicidad del Código Penal y el amplio poder policial para arrestar cualquier persona considerada como sospechosa por la policía, la llamada "detención por sospecha" regulada en el Código de Procedimiento Penal. A continuación se examinará brevemente la discusión parlamentaria sobre la creación del control de identidad y las discusiones que siguieron con posterioridad en relación con las modificaciones de dicho poder, con el propósito de iluminar algunos de los problemas que para la justicia implica su ejercicio.

\subsubsection{De la detención por sospecha al control de identidad.}

Como explica Claudio Fuentes, en los primeros años posteriores a la dictadura el gobierno efectuó una serie de reformas legales con el objeto de compatibilizar las leyes chilenas con las exigencias del derecho internacional de los derechos humanos ${ }^{3}$. En el sistema penal, se introdujeron garantías procedimentales básicas y se hicieron otras reformas legales con el objeto de proteger los derechos de los detenidos y presos, tales como la delimitación del uso de celdas de aislamiento, protección contra la tortura, restricciones a la prisión preventiva y a la imposición de la pena de muerte ${ }^{4}$. Es en este contexto que en 1993 se propone por moción parlamentaria la eliminación de la detención por sospecha regulada en el artículo 260 del Código de Procedimiento Penal ${ }^{5}$.

Dicho artículo facultaba a la policía para detener en el espacio público a quien anduviere con disfraz o que de otra manera ocultara su verdadera identidad. También podía detener a aquellos encontrados en lugares, en horas o circunstancias que hicieran sospechar "malos designios". Por último, personas sin trabajo u hogar estable, personas pidiendo limosna en las calles, alcohólicos, drogadictos, homosexuales, comerciantes ambulantes y el "delincuente habitual", entre otros, podían ser sujetos al control policial. La detención en las comisarías o en las prisiones podía durar hasta 48 horas sin control judicial alguno. Dicha privación de libertad tenía como claro propósito remover de las calles a aquellos considerados como peligrosos o molestos para el resto de la sociedad.

La discusión parlamentaria sobre la derogación de la detención por sospecha se desarrolló en torno a dos principales temáticas: en primer lugar, se discutió las posibles consecuencias discriminatorias que podía traer su uso. En segundo lugar, se debatió acerca de la necesidad de que la policía contara con este tipo de facultades preventivas ${ }^{6}$. Para quienes abogaban la derogación de la detención por sospecha el principal problema estaba en la discriminación que sufrían los jóvenes, quienes eran sometidos a controles arbitrarios en los espacios públicos ${ }^{7}$. De acuerdo a estos parlamentarios, Carabineros confundía la moda de los

\footnotetext{
${ }^{3}$ FUENTES, Claudio, "Violent Police, Passive Citizens", en: PERUZZOTTI, Enrique y SMULOVITZ, Catalina (Eds.), Enforcing the Rule of Law. Social Accountability in the New Latin American Democracies, Pittsburgh: University of Pittsburgh Press, 2006, p.142.

${ }^{4}$ Ley $\mathrm{N}^{\circ} 19.029$ de 1991 y N 19.047 de 1992.

${ }^{5}$ Moción Diputados Mario Devaud Ojeda, Juan Pablo Letelier Morel, Carlos Montes Cisternas, Adriana Muñoz D'Albora y Andrés Palma Irarrázabal.

${ }^{6}$ Historia de la Ley $\mathrm{N}^{\circ} 19.567$, Biblioteca del Congreso Nacional de Chile.

${ }^{7}$ Ibíd pp. 29, 40, 41 y 91.
} 
Polít. crim. Vol. 10, № 19 (Julio 2015), Art. 8, pp. 234-265.

[http://www.politicacriminal.cl/Vol_10/n_19/Vol10N19A8.pdf]

jóvenes de los 90 por un $\operatorname{disfraz}^{8}$. De esta forma, zapatillas, pelo largo y aritos eran considerados sospechosos, dando lugar al constante hostigamiento de los jóvenes en las calles 9 .

A pesar de que la principal preocupación en la discusión era la discriminación de los jóvenes en general, algunos parlamentarios agregaron que había un grupo específico de jóvenes más vulnerable al abuso policial ${ }^{10}$. De acuerdo a estos parlamentarios las principales víctimas de la policía era los jóvenes de escasos recursos ${ }^{11}$. En primer lugar, eran esos jóvenes lo más expuestos a ser controlados dado su mayor presencia en las calles. Al no contar con espacio suficiente en sus propias casas los jóvenes eran forzados a reunirse en el espacio público ${ }^{12}$. En segundo lugar, se señaló el problema de la falta de poder de estos grupos para cuestionar comportamientos arbitrarios de Carabineros ${ }^{13}$. Además, se reflexionó sobre las consecuencias que para los jóvenes de escasos recursos traía esta excesiva vigilancia policial. Los parlamentarios señalaron la creación de sentimientos de inferioridad y vulnerabilidad ${ }^{14}$, la estigmatización social de los jóvenes controlados por la policía y eventualmente sometidos a prisión ${ }^{15}$, la creación de desconfianza y posibilidades de enfrentamiento entre Carabineros y comunidades de los barrios más pobres donde frecuentemente se experimentaba un uso abusivo del control policial $^{16}$.

Los parlamentarios que abogaron por la derogación estaban también preocupados por la falta de control externo al ejercicio del poder policial. Se señaló que a pesar del alto número de detenciones de jóvenes, esto no era controlado por los tribunales y la policía no mantenía datos confiables sobre el uso de su facultad ${ }^{17}$. Por último, se argumentó acerca de la inefectividad de la detención por sospecha para controlar la criminalidad, señalando que solo un $2 \%$ de las personas sujetas a control se había involucrado en algún momento de su vida en actividades delictivas ${ }^{18}$.

A pesar de estas críticas, los parlamentarios de oposición defendieron la mantención de la disposición por dos razones. En primer lugar, argumentaron que de ser efectiva la existencia de discriminación en el uso de la facultad policial esto no debía motivar su eliminación. La disposición legal exigía a la policía actuar de manera fundada cuando contara con evidencia de la comisión de un delito, en consecuencia, la detención por sospecha no debía ser eliminada sino que era Carabineros quienes debían modificar sus prácticas de manera de cumplir la ley ${ }^{19}$. En segundo lugar, señalaron la necesidad de

\footnotetext{
${ }^{8}$ Ibíd pp. 24 y 40.

${ }^{9}$ Ibíd p. 114.

${ }^{10}$ Ejemplo: Diputados Jaime Naranjo Ortiz, Juan Carlos Latorre Carmona y Andrés Palma Irarrázabal.

${ }^{11}$ Historia de la Ley $\mathrm{N}^{\circ} 19.567$, p. 51.

${ }^{12}$ Ibíd pp. 29 y 114.

${ }^{13}$ Ibíd p. 42.

${ }^{14}$ Ibíd p. 214.

${ }^{15}$ Ibíd p. 218.

${ }^{16}$ Ibíd pp. 29, 33, 39, 50 y 216.

${ }^{17}$ Ibíd pp. 40 y 42.

${ }^{18}$ Ibíd p. 33.

${ }^{19}$ Ibíd p. 46.
} 
IRARRÁZABAL, Paz. "Igualdad en las calles en Chile: el caso del control de identidad".

otorgar facultades preventivas a la policía de manera de proteger a los ciudadanos de los criminales $^{20}$. Esto último, que resultó siendo el principal argumento de los partidos de derecha, apuntaba a un conflicto entre los "derechos de los criminales" y los derechos del resto de los ciudadanos, frente al cual era ineludible asumir cierto costo social con el objeto de poder proteger la seguridad pública y la libertad de los ciudadanos ${ }^{21}$.

Finalmente, el parlamento acogió la idea sobre la existencia de un conflicto de intereses y decidió crear la facultad policial de controlar la identidad en reemplazo de la detención por sospecha. De acuerdo a este nuevo poder la policía estaba facultada para requerir identificación a cualquier persona cuando existiese evidencia de la comisión de un crimen. La identificación podía efectuarse por cualquier medio y en caso de negativa a proveer dicha información, la persona podía ser conducida a la comisaría, donde se podía imponer una multa o citación a tribunales. Se estableció también una sanción disciplinaria en caso de abuso policial en el ejercicio de la facultad.

Aun cuando algunos parlamentarios denunciaron que este nuevo poder iba a generar las mismas violaciones de derechos de los grupos desaventajados que había ocasionado la detención por sospecha ${ }^{22}$, la disposición fue aprobada con la convicción de que lograba un adecuado balance en el respeto de los derechos de todos los posibles involucrados. Se argumentó que la facultad era lo suficientemente limitada, dado que solo se podía exigir identificación en relación con la comisión de los delitos más graves ${ }^{23}$, que la exigencia de identificación era una carga mínima a los ciudadanos ${ }^{24}$, y que "quien nada hace, nada teme" 25 ; en otras palabras, que sólo criminales e inmigrantes sin papeles se negarían a cumplir con la exigencia policial $^{26}$.

La Ley 19.567 fue aprobada en 1998, remplazando la detención por sospecha por el control de identidad.

\subsubsection{El intento por derogar el control de identidad y su posterior expansión.}

La nueva facultad policial de control de identidad creada en 1998 vio amenazada su existencia con la discusión de la reforma al proceso penal que se había iniciado en 1995. La reforma buscaba reemplazar el procedimiento inquisitorial que regía en Chile desde 1906, el cual implicaba serias violaciones al principio de presunción de inocencia y debido proceso. En este contexto, el control de identidad no tenía cabida. Efectivamente, el proyecto de ley original del nuevo Código Procesal Penal no contemplaba dicha facultad ${ }^{27}$. La incorporación del control de identidad fue propuesta por los senadores designados Cordero y Stange, quienes se habían desempeñado como generales directores de Carabineros. Partidos de derecha apoyaron esta propuesta acudiendo nuevamente al

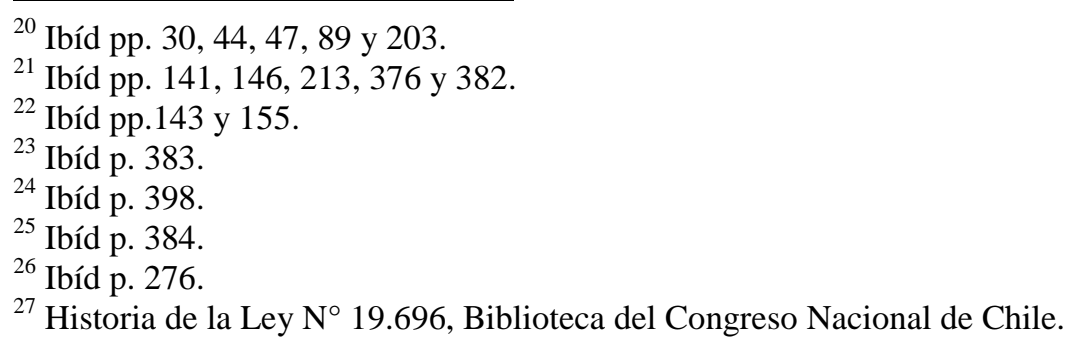


Polít. crim. Vol. 10, № 19 (Julio 2015), Art. 8, pp. 234-265.

[http://www.politicacriminal.cl/Vol_10/n_19/Vol10N19A8.pdf]

argumento sobre la necesidad de mantener un equilibrio entre los derechos de algunos y la seguridad del resto de la comunidad. Finalmente, el nuevo Código Procesal Penal mantuvo la regulación del control de identidad que estableciera la Ley 19.567 con algunas pequeñas modificaciones. Se estableció la posibilidad de identificarse a través del registro de las huellas dactilares y dispuso un tiempo límite de 4 horas para la realización del procedimiento de identificación.

Desde la entrada en vigencia del Código Procesal Penal en el 2000, una serie de reformas legales han ido expandiendo los poderes y condiciones para el ejercicio del control de identidad (en el 2002, 2004 y 2008). Estas reformas fueron el resultado de un amplio consenso entre los diferentes partidos políticos sobre la necesidad de endurecer la lucha contra la delincuencia, siendo necesario ampliar las facultades preventivas de la policía. El discurso político de "ley y orden" formulado por partidos de derecha ganó prominencia en la discusión pública a consecuencia en gran medida del privilegiado acceso de dichos partidos a los medios de comunicación ${ }^{28}$. Este discurso creó una percepción pública de inseguridad y de que la reforma penal había protegido en exceso a los criminales, aun cuando, como explica María Inés Horvitz, en la realidad no existía evidencia de un aumento de la criminalidad en el espacio público y la cantidad de personas en prisión aumentaba ${ }^{29}$.

La primera reforma al control de identidad se produjo con la Ley 19.789 del 2002. Esta ley buscaba sancionar de forma más efectiva faltas y desórdenes, por considerar que estos tenían un enorme impacto en la vida cotidiana de la gente ${ }^{30}$. Hubo un amplio consenso entre los parlamentarios de diferentes partidos políticos sobre la necesidad de responder al sentimiento de impunidad y desamparo de la comunidad ${ }^{31}$. El control de identidad sufrió tres principales modificaciones: en primer lugar, se incorporaron las faltas y simple delitos entre los presupuestos para el ejercicio del control. En segundo lugar, se autorizó a la policía para registrar la ropa, equipaje y automóvil de la persona controlada. Finalmente, el límite para la realización del procedimiento aumentó a 6 horas. En la discusión parlamentaria se argumentó que el requerimiento de identificación era una carga razonable a la privacidad de los ciudadanos y que nadie podía sentirse vulnerado en su dignidad al ser sometido a este método de control ${ }^{32}$.

Dos años después, la Ley 19.942 del 2004 modificó la redacción de la disposición que establecía el control de identidad de manera de que se entendiera que el ejercicio del poder

\footnotetext{
${ }^{28}$ FUENTES, "Violent Police", cit. nota n 3, p.163.

${ }^{29}$ HORVITZ, María Inés, "Seguridad y garantías: derecho penal y procesal penal de prevención de peligros", Revista de Estudios de la Justicia, 16 (2012), pp. 99-118. La monopolización de la agenda pública por el discurso de ley y orden no solo resultó en la expansión de las facultades preventivas de la policía para controlar el espacio público sino que afectó el completo nuevo sistema criminal debilitando su original propósito de proteger los derechos humanos. Por ejemplo, se aumentaron las causales de prisión preventiva, se aumentaron las penas para faltas y hubo en dicho periodo un significativo aumento de la población penal la que alcanzó un máximo de 247 presos por 100.000 habitantes en 2014, uno de los más altos índices de Sud América. Ver INTERNATIONAL CENTRE FOR PRISON STUDIES: Chile, en http://www.prisonstudies.org/country/chile [visitado el 26.09.14].

${ }^{30}$ Historia de la Ley $\mathrm{N}^{\circ} 19.789$, Biblioteca del Congreso Nacional de Chile, pp. 6 y 39.

${ }^{31}$ Ibíd p. 39.

${ }^{32}$ Ibíd pp. 27 y 42.
} 
IRARRÁZABAL, Paz. "Igualdad en las calles en Chile: el caso del control de identidad".

de control no era facultativo para la policía sino que una obligación. También se estableció que cuando la persona se negaba a proveer su identificación, la policía podía arrestarla toda vez que se entendió que esta negación constituía una falta. En la discusión de esta ley los parlamentarios señalaron que en el pasado se había dado demasiada consideración a los derechos humanos de unos pocos, lo que había puesto en peligro la seguridad de la mayoría de los ciudadanos y que para enfrentar el aumento de la criminalidad se requería dar mayor flexibilidad a la policía ${ }^{33}$.

La última reforma del control de identidad se realizó con la Ley 20.253 del 2008. Para ese entonces el pánico moral sobre la criminalidad era aún más patente, llevando al gobierno de la Concertación a proclamar este asunto como su principal preocupación y creando un plan político que denominaron "Agenda Corta", el cual comprendía varias leyes dirigidas a combatir el crimen las que debían ser discutidas con rapidez por el Congreso ${ }^{34}$. Argumentando otra vez que el sistema legal otorgaba demasiada protección a los criminales, sacrificando el derecho de las víctimas y la efectividad de la policía, los parlamentarios modificaron la facultad de controlar la identidad de tres formas ${ }^{35}$. En primer lugar, se aumentó el tiempo que podía durar el procedimiento de control de identidad. En segundo lugar, se buscó clarificar la facultad de la policía para detener en el procedimiento a personas con órdenes de detención pendiente o que fueran encontradas con objetos ilícitos. Finalmente, los parlamentarios agregaron la facultad de la policía para someter a control a aquellos que cubrieran su cara para ocultar su identidad.

La última modificación señalada fue objeto de especial debate parlamentario. Por una parte, se justificó la norma argumentando que las personas cubrían sus caras en las protestas con el objeto de dañar la propiedad ${ }^{36}$. En oposición algunos miembros de la Concertación señalaron que esta disposición constituía un retorno definitivo a la detención por sospecha. Además, con dicho cambio se producía una separación definitiva entre el control de identidad y la ocurrencia de un delito ${ }^{37}$.

\subsubsection{Recapitulación.}

La creación y evolución de la facultad policial para controlar la identidad desde 1998 ilustra importantes aspectos de la discusión sobre los derechos de las personas en el espacio público en Chile. La creación del control de identidad se relacionó con un especial momento para la construcción de la democracia en Chile y fue pensado como un avance en la protección de las libertades individuales. En efecto, la facultad de la policía para exigir identificación en las calles en caso de que existiera sospecha de la comisión de un crimen fue un limitado sustituto de la detención por sospecha, extenso poder que permitía derechamente arrestar a ciertas personas indeseadas, a aquellos que ocultaran su identidad o cuando se pudiere sospechar de sus malos designios.

\footnotetext{
${ }^{33}$ Historia de la Ley $\mathrm{N}^{\circ} 19.942$, Biblioteca del Congreso Nacional de Chile pp. 5 y 35.

${ }^{34}$ Historia de la Ley $\mathrm{N}^{\circ} 20.253$, Biblioteca del Congreso Nacional de Chile.

${ }^{35}$ Ibíd pp. 175, 229 y 479.

${ }^{36}$ Ibíd p. 73.

${ }^{37}$ Ibíd pp. 73, 178, 180 y 317.
} 
Polít. crim. Vol. 10, № 19 (Julio 2015), Art. 8, pp. 234-265.

[http://www.politicacriminal.cl/Vol_10/n_19/Vol10N19A8.pdf]

Con la introducción del control de identidad se pretendió evitar atar de manos a la policía y lograr el adecuado balance entre las libertades de los ciudadanos. Sin embrago, desde el 2002 un pánico moral sobre la criminalidad impactó el discurso político, transformando el control de identidad en un poder similar al que pretendía reemplazar. En 2002, las reformas al control de identidad implicaron la incorporación de las faltas y también facultaron a la policía para realizar registros en los bienes de las personas controladas. En el 2004 se le otorgó a la policía el poder de proceder a un arresto a consecuencia del control de identidad. Finalmente, en 2008 el uso de cierta ropa cubriendo la cara se transformó en una causa suficiente para la realización del control. Los parlamentarios consideraron en ese entonces que el aumento del poder de control era un mínimo necesario para mantener la seguridad y orden en las calles.

\section{El uso del control de identidad.}

La discusión suscitada en la creación y reforma del control de identidad revela importantes problemáticas relacionadas con su ejercicio que requieren ser evaluadas. Es fundamental conocer con qué frecuencia el control es usado, su efectividad en la prevención del crimen y su impacto en los derechos de aquellos sujetos al control. Sin embargo, en Chile se carece de información mínima acerca del uso de la facultad policial. En esta parte del artículo exploraré algunas pistas sobre su posible uso y propondré algunas razones que pueden dar cuenta de la falta de antecedentes en la materia.

De acuerdo con las estadísticas de Carabineros, en 2014 se realizaron 1.853 .244 controles de identidad a lo largo del país ${ }^{38}$. No fue posible acceder a información oficial adicional sobre el uso del control y antecedentes de las personas sujetas a él ${ }^{39}$. A pesar de la falta de datos oficiales, en la sociedad civil es posible encontrar denuncias de uso abusivo de esta facultad policial. Así, por ejemplo, se ha denunciado controles masivos de identidad a estudiantes $^{40}$ y comunidades Mapuche ${ }^{41}$. También organizaciones de defensa de los

\footnotetext{
${ }^{38}$ Carabineros en cifras, en http://www.carabineros.cl/cifras/cifras2014/pdf/carabineros_en_cifras_2014.pdf [visitado el 28.04.15]. En 2013, se efectuaron 1.732 .928 controles de identidad y 1.142 personas fueron arrestadas por negativa a identificarse. Información obtenida a través de solicitud de acceso a la información presentada a Carabineros de Chile (Decisión AD009W0025585, 3 Julio 2014).

${ }^{39}$ Presenté dos solicitudes de acceso a la información a Carabineros acerca del uso del control de indetidad. Obtuve como respuesta solo el número total de controles de identidad efectuados por año calendario y por comuna. No hubo respuesta en cuanto al perfil de las personas sometidas a control, circunstancias y resultados de los controles.

${ }^{40}$ CENTRO DE DERECHOS HUMANOS DE LA UNIVERSIDAD DIEGO PORTALES, Informe Anual sobre los Derechos Humanos en Chile 2013, pp. 261-62 en: http://www.derechoshumanos.udp.cl/index.php/informe-anual/repository/func-startdown/17/ [visitado el 12.11.14]. Ver también INSTITUTO NACIONAL DE DERECHOS HUMANOS, Reporte Anual 2013 Programa Derechos Humanos y Función Policial, en: http://www.camara.cl/pdf.aspx?prmID=20672\&prmTIPO=DOCUMENTOCOMISION [visitado el 28.11.14]. De acuerdo a dichos informes Carabineros realizó controles masivos de identidad a estudiantes que se dirigían a lugares donde se efectuarían marchas autorizadas.

${ }^{41}$ Ver por ejemplo Meli Wixan Mapu, Masivo control de identidad a miembros de Comunidad Autónoma de Teтисиicui en http://meli.mapuches.org/spip.php?article2764 [visitado el 26.09.14].
} 
IRARRÁZABAL, Paz. "Igualdad en las calles en Chile: el caso del control de identidad".

derechos de LGTB $^{42}$ y de trabajadoras sexuales ${ }^{43}$ han denunciado en varios informes prácticas abusivas de Carabineros.

Un importante caso de abuso policial fue precisamente el resultado de un recurso de amparo constitucional interpuesto por una trabajadora sexual transexual, quien acusó a Carabineros de haberla detenido de forma violenta y haberla mantenido en la comisaría por varias horas a pesar de que portaba sus documentos de identificación ${ }^{44}$. Carabineros negó el uso de violencia y justificó el procedimiento de control de identidad en el contexto de un plan para controlar el comercio sexual en las calles. En un intento por justificar la procedencia del procedimiento, Carabineros señaló que en el caso se habría realizado el control de un grupo de individuos "de los cuales algunos presentando su cédula de identidad masculinas estaban disfrazados y caracterizados como mujeres, y otros no portaban su cédula de identidad" (considerando 2). La Corte de Apelaciones acogió el recurso declarando la ilegalidad de la actuación policial al no haber existido los antecedentes fácticos que habilitan el control de identidad. Señaló que el actuar de Carabineros afectaba la libertad personal y que la facultad policial en cuestión no podía usarse para el manejo del comercio sexual (considerando 4).

Sin embargo, estas denuncias sobre del uso del control de identidad provenientes de la sociedad civil son excepcionales. Esto puede llevarnos a pensar que la facultad policial es, por lo general, ejercida de forma apropiada. Dicha hipótesis puede ser respaldada por la confianza que los chilenos muestran en Carabineros, institución considerada como una de las policías menos corrupta y abusiva de Latinoamérica ${ }^{45}$. Sin embrago, cierta evidencia hace esta hipótesis cuestionable. En primer lugar, la inexistencia de un mínimo de información confiable sobre el uso del control de identidad es una muy persuasiva indicación de la falta de control de la actuación policial y, por tanto, la existencia de riesgo de abuso. En segundo lugar, en los últimos años ha habido un constante aumento de acusaciones de violencia policial y detenciones discriminatorias. Por ejemplo, Carlos Fuentes ha señalado el aumento sostenido de denuncias por violencia policial en las cortes militares desde $2004^{46}$. Así también, un creciente número de detenciones policiales han sido declaradas ilegales por la justicia penal. De acuerdo a la Defensoría Penal Pública, en el 2012 23.7\% de aquellos arrestos declarados ilegales afectaron a indígenas, 17,1\% afectaron

\footnotetext{
${ }^{42}$ MOVIMIENTO DE LIBERACIÓN HOMOSEXUAL, XII Informe Anual de Derechos Humanos de la Diversidad Sexual en Chile 2013, p. 59 en: http://www.movilh.cl/documentacion/XII-Informe-DDHH-de-ladiversidad-sexual-Movilh-2013-\%20web-baja.pdf [visitado el 26.09.14].

${ }^{43}$ FUNDACION SAVIA, Investigación de monitoreo y valoración de la política pública de prevención y atención intehral del VIH y SIDA en población de mujeres ejercen el comercio sexual 2012, pp. 24-26 en: http://www.fundacionsavia.cl/media/uploads/docs/INVESTIGACION_COMERCIO_SEXUAL_- 2012.pdf [visitado el 28.04.14].

${ }^{44}$ Caso 1393-2012, 19.07.2012, Corte de Apelaciones de Santiago.

${ }^{45}$ De acuerdo a Latinobarómetro 2006 Chile es el país de la región donde los ciudadanos muestran más confianza en su policía.

${ }^{46}$ FUENTES, Claudio, "Denuncias por violencia policial: cifras para preocuparse", El Mostrador (Santiago, 17 Enero 2014) en http://www.elmostrador.cl/opinion/2014/01/17/denuncias-por-violencia-policial-cifraspara-preocuparse/ [visitado el 26.09.14].
} 
Polít. crim. Vol. 10, № 19 (Julio 2015), Art. 8, pp. 234-265.

[http://www.politicacriminal.cl/Vol_10/n_19/Vol10N19A8.pdf]

a jóvenes y $13.5 \%$ a extranjeros ${ }^{47}$. Aunque estas cifras no se refieren directamente al ejercicio del control de identidad, otorgan ciertas pistas sobre cómo la policía está ejerciendo sus labores.

A pesar de que múltiples causas pueden explicar la falta de vigilancia institucional del uso del control de identidad, señalaré acá solo dos posibles razones. En primer lugar, no es difícil imaginar que las personas que enfrentan con mayor cotidianidad a la policía carecen del sustento necesario o incentivos para desafiar su actuación. Para ellos el control de identidad puede implicar una pequeña molestia o un detalle en el contexto de las experiencias de discriminación que soportan diariamente en los espacios públicos (lo que no implica que el daño final de ese constante hostigamiento sea enorme en el bienestar de dichas personas ${ }^{48}$ ). Esta situación se agrava mientras mayor sea la condición de marginalidad o situación de vulnerabilidad de los individuos controlados. La invisibilización y la falta de poder de aquellos que se enfrentan con mayor frecuencia al control policial son, en mi opinión, una posible explicación -la principal- de la falta de denuncias.

Una segunda posible explicación de la falta de denuncias de ejercicio abusivo del control de identidad dice relación con la ausencia o insuficiencia de canales institucionales para formular denuncias contra Carabineros. En primer lugar, los delitos cometidos por Carabineros están bajo la jurisdicción de las cortes militares, quienes conocen de los casos en procedimientos secretos. Esta regulación plantea serios problemas de imparcialidad e independencia de las cortes afectando los más básicos principios de debido proceso. De acuerdo a Fuentes, hay poco incentivo para interponer denuncias en estas cortes, porque la posibilidad de obtener un resultado positivo es virtualmente cero. Señala que durante el periodo 1990-2000 menos de un 3\% de los casos presentados en las cortes militares terminaron con una sentencia condenatoria de Carabineros, situación que ha empeorado con los años ${ }^{49}$. De hecho, de acuerdo al Informe Anual del Instituto Nacional de Derechos Humanos de 2013, durante los años 2005 - 2011 solo un $0.48 \%$ de los casos conocidos por las cortes militares terminaron con sentencias condenatorias ${ }^{50}$.

Adicionalmente, Chile carece de mecanismos administrativos de reclamo flexibles y accesibles, que normalmente se encuentran en otras jurisdicciones, tales como defensores del pueblo o comisiones independientes de vigilancia de la labor de la policía. Por su parte, los procedimientos ordinarios de justicia civil son inadecuados para conocer de estos asuntos de abuso policial. Estos procedimientos son caros, lentos y burocráticos. Además, la asistencia legal es muy limitada sobre todo cuando se trata de demandar al Estado. Por

47 DEFENSORÍA PENAL PÚBLICA, Informe Estadístico Anual 2012, p. 9, en: http://www.dpp.cl/resources/upload/files/documento/9a4c122934927b0ee2c37842994663e5.pdf [visitado el 26.09.14]

${ }^{48}$ Como fuera descrito por Goffman en su estudio sobre estigma publicado en 1963, las consecuencias de tener que lidiar con prejuicios en constantes encuentros sociales pueden ser pequeñas si se considera cada encuentro en particular pero si se consideran los múltiples encuentros las consecuencias son inmensas para la persona estigmatizada. GOFFMAN, Erving, Stigma, Nueva York: Simon and Schuster, 1986, p. 48.

${ }^{49}$ FUENTES, "Violent Police", cit. nota n 3, p.150.

${ }^{50}$ INSTITUTO NACIONAL DE DERECHOS HUMANOS, Reporte Anual 2013, Funcion Policial, cit. nota $\mathrm{n}^{\circ} 40$, p. 73. 
último, la acción de antidiscriminación que fuera incorporada recientemente a nuestro sistema legal tiene serios déficits que desincentivan su uso; por ejemplo, en el caso de perder se puede estar en la obligación de pagar una multa y, aun en el caso de que prospere la acción, no se contempla una indemnización a favor de la víctima. Como resultado de todo lo anterior, el hecho de que se conozcan pocos casos de abuso policial difícilmente puede ser tomado como un indicador de correcto desempeño policial en el uso del control de identidad.

Una fuente adicional de claves sobre cómo se ejerce en la práctica el control de identidad que será explorada en este artículo dice relación con controles de legalidad efectuado en causas penales. Las Cortes de Apelaciones y Suprema han conocido de estos casos por dos vías. En primer lugar, los tribunales superiores se han pronunciado a propósito de las apelaciones de decisiones de jueces de garantía que han declarado ilegales arrestos efectuados como consecuencias de controles de identidad que no han cumplido con los requisitos establecidos en la ley. Un segundo grupo de casos consiste en apelaciones de sentencias definitivas de tribunales penales en casos en que la prueba haya sido excluida o incluida, dependiendo de lo resuelto con respecto a la legalidad del uso del control de identidad.

En la mayoría de los casos las cortes superiores han revertido las decisiones de los jueces penales que han declarado la ilegalidad del control de identidad. Los principales criterios que se desprenden de dichas decisiones son los siguientes:

1. No se requiere de la existencia previa de conductas sospechosas de un individuo para llevar a cabo un control de identidad. Carabineros puede realizar controles en "procedimientos de rutina", es decir, pueden parar y exigir identificación a cualquier persona sin que exista previamente una causa de sospecha vinculada a la comisión de una ofensa $^{51}$.

2. El hecho de que una persona se ponga nerviosa ante la presencia policial es indicio que habilita la realización de un control de identidad ${ }^{52}$. Como fuera señalado por la Corte de Apelaciones de Arica en una sentencia del 2007, el nerviosismo ante la presencia policial es una "reacción que, de acuerdo con la lógica y las máximas de la experiencia, solamente se produce en una persona que teme ser sorprendida en un actuar incorrecto",53.

3. Encontrarse en un lugar y hora inapropiado es suficiente evidencia para controlar la identidad de una persona. Las cortes han considerado sospechosa la presencia de una persona en lugares que Carabineros considera "peligrosos" 54 o donde la policía ha detectado la ocurrencia de robos o tráfico de drogas ${ }^{55}$. Por ejemplo, la Corte de Apelaciones de San Miguel, el año 2010, señaló que Carabineros podía controlar a personas saliendo de La Legua, uno de los barrios más estigmatizado de Santiago, porque de acuerdo a

\footnotetext{
${ }^{51}$ Sentencias 258-2006, 15.03.2006, C.A. Santiago; 287-2007, 19.12.2007, C.A. Antofagasta; 8346-2012, 23.01.2013, Corte Suprema; 100-2013, 11.02.2013, C.A. San Miguel.

52 Sentencias 156-2005, 20.07.2005, C.A. Antofagasta; 120-2006, 24.05.2006, C.A. Arica; 258-2006, 15.03.2006, C.A. Santiago; 111-2007, 07.06.2007, C.A. Antofagasta; 8346-2012, 23.01.2013, Corte Suprema; 100-2013, 11.02.2013, C.A. San Miguel.

${ }^{53}$ Sentencia 120-2006, 24.05.2006, C.A. Arica, considerando 7.

${ }^{54}$ Sentencia 120-2006, 24.05.2006, C.A. Arica.

${ }^{55}$ Sentencias 156-2005, 20.07.2005, C.A. Antofagasta; 311-205, 07.11.2005 C.A. Puerto Montt; 283-2007, 30.07.2007 C.A. Rancagua; 819-2010, 05.07.2010, C.A. San Miguel; 8346-2012, 23.01.2013, Corte Suprema.
} 
Polít. crim. Vol. 10, № 19 (Julio 2015), Art. 8, pp. 234-265.

[http://www.politicacriminal.cl/Vol_10/n_19/Vol10N19A8.pdf]

Carabineros este era un lugar de constante tráfico de drogas ${ }^{56}$. Las cortes también han considerado que Carabineros puede controlar a una persona considerada como un extraño en un barrio específico ${ }^{57}$.

En casos excepcionales las cortes han establecido la ilegalidad del uso del poder policial de control de identidad. En estos casos las cortes han exigido que la policía cuente con evidencia ex ante al ejercicio del $\operatorname{control}^{58}$, han declarado que estar nervioso frente a Carabineros no es suficiente evidencia para realizar un $\operatorname{control}^{59}$ y que el uso del poder no se encuentra justificado si la persona se aproximó a la policía pidiendo ayuda ${ }^{60}$. Las cortes también han exigido la existencia de indicios fundados en conductas concretas de la persona que permitan suponer su participación en un delito. En un caso del 2007, por ejemplo, la Corte de Apelaciones de Concepción señaló que "criterios fundados en el aspecto personal del sujeto, origen, condición social, religiosa o lugar de domicilio" no pueden ser considerados por Carabineros para el ejercicio del control ${ }^{61}$.

En aquellos casos en que se ha considerado que existió un uso ilegal del control de identidad se ha reconocido una violación a los derechos fundamentales de debido proceso, privacidad, libertad personal y seguridad. Así, la Corte de Apelaciones de Concepción señaló: “...el control de identidad en sí afecta derechos garantizados por la Constitución, libertad personal y ambulatoria, por lo que el poder debe interpretarse restrictivamente"62.

En conclusión, el uso de la facultad para controlar la identidad no ha estado sujeto a una adecuada vigilancia y control, lo cual es preocupante dado que, de acuerdo a las cifras de Carabineros, cerca de dos millones de controles son efectuados al año. De las pistas recabadas en esta parte se pueden señalar, por el momento, que han sido objeto de control policial en Chile: estudiantes, Mapuche, mujeres transexuales, trabajadoras sexuales, personas que se muestran nerviosas ante la presencia policial y aquellos "fuera de lugar" o en lugares "sospechosos". Lo hasta aquí señalado puede parecer demasiado especulativo dada la limitada información disponible por lo que mirar a alguna experiencia comparada donde exista mayor información y control de la actividad policial será de ayuda en este análisis.

\section{La experiencia en el Reino Unido.}

La información disponible en Chile sobre el uso del control de identidad no nos permite hacer una evaluación completa sobre la necesidad e impacto de esta institución. Sin embargo, las pocas pistas señaladas más arriba permiten hacerse una idea sobre los riesgos que el uso de la facultad puede suponer para grupos más desaventajados en Chile. Dada la existencia de dicho riesgo se intentará en esta parte avanzar en una más completa

\footnotetext{
${ }^{56}$ Sentencia 819-2010, 05.07.2010, C.A. San Miguel.

${ }^{57}$ Sentencias 156-2005, 20.07.2005, C.A. Antofagasta y 311-205, 07.11.2005 C.A. Puerto Montt.

${ }^{58}$ Sentencia 546-2007, 23.11.2007 C.A. Concepción.

${ }^{59}$ Sentencia 72-2005, 07.04.2005 C.A. Antofagasta.

${ }^{60}$ Sentencia 279-2007 20.12.2007 C.A. Antofagasta.

${ }^{61}$ Sentencia 546-2007, 23.11.2007 C.A. Concepción, considerando 5.

${ }^{62}$ Sentencia 546-2007, 23.11.2007 C.A. Concepción, considerandos 3 y 4.
} 
evaluación recurriendo a la discusión desarrollada en el Reino Unido en relación al poder policial denominado stop and search (SAS).

Algunas razones que aconsejan atender a dicha discusión son las siguientes: en primer lugar, en el Reino Unido desde los años 60 se ha desarrollado una extensa discusión acerca del uso de SAS y su impacto en la comunidad. Esta discusión se ha fundado en abundante evidencia proveniente de investigaciones académicas y datos oficiales del gobierno. En segundo lugar, es posible hacer un cierto paralelo entre la historia de la regulación del SAS y la del control de identidad en Chile. Ambos poderes se originaron con una década de diferencia como un intento de racionalizar facultades policiales que fueron consideradas como discriminatorias respecto de grupos vulnerables. En tercer lugar, el caso del SAS puede resultar particularmente aleccionador debido a que, a pesar de los serios intentos por controlar el actuar policial, ciertos resultados discriminatorios continúan manifestándose con graves consecuencias no solo para los derechos de las personas sino que, en último término, para la comunidad en general.

En consecuencia, sin desconocer que el funcionamiento de las facultades policiales se vincula a especificidades históricas y culturales sobre criminalidad, grupos desaventajados y arreglos institucionales, la discusión del SAS puede proveer de argumentos y evidencia que iluminen en alguna medida los riesgos que implica nuestro control de identidad.

\subsection{Stop and search y su control.}

En el Reino Unido distintas leyes otorgan facultades a la policía para parar y registrar a las personas en el espacio público. Sin embargo, la mayoría de los SAS que se realizan en la práctica, cerca de un millón de controles al año ${ }^{63}$, se efectúan de acuerdo a la Ley de Policía y Evidencia Criminal de 1984 (conocida como PACE). Esta ley establece que para poder ejercer la facultad de SAS el agente policial debe tener suficientes indicios para sospechar que una determinada persona posee un objeto robado o un artículo prohibido por la ley (tales como armas, drogas u otros objetos vinculados a la comisión de un delito) ${ }^{64}$. Esta regulación es el resultado de una larga evolución legislativa en la que se ha buscado limitar el poder de policía para controlar a las personas en el espacio público.

Con anterioridad a PACE existían varias leyes que permitían a la policía parar y registrar individuos en la búsqueda de objetos ilícitos ${ }^{65}$. Además, la Ley de Vagancia de 1824 permitía a la policía parar, registrar y eventualmente arrestar por un periodo de hasta tres meses a "personas sospechosas o conocidos ladrones"66. Estas leyes que eran conocidas como "Sus laws" (por su enfoque en "personas sospechosas" [suspected persons]) dieron lugar a intensas controversias por su desproporcionado uso en contra de grupos minoritarios, en particular personas de raza negra. El resentimiento generado por la excesiva vigilancia a la que eran sometidos grupos minoritarios alcanzó su máxima

\footnotetext{
${ }^{63}$ STRICKLAND, Pat, Stop and Search, Londres: Home Affairs Section, House of Commons Library, 2014.

${ }^{64}$ Sección 1 (3) de la Ley de Policía y Evidencia Criminal de 1984.

${ }^{65}$ Ejemplo: sección 66 de la Ley de la Policía de Londres de 1839.

${ }^{66}$ DELSOL, Rebekah y SHINER Michael, "Regulation Stop and Search: A Challenge for Police and Community Relations in England and Wales”, Critical Criminology, 14 (2006), pp. 241-263, p. 243.
} 
Polít. crim. Vol. 10, № 19 (Julio 2015), Art. 8, pp. 234-265.

[http://www.politicacriminal.cl/Vol_10/n_19/Vol10N19A8.pdf]

expresión en violentos desórdenes en diversas ciudades del Reino Unido en los años 1980 y $1981^{67}$.

Finalmente estas leyes fueron derogadas y remplazadas en 1984 por la institución de SAS contemplada en PACE ${ }^{68}$. Desde entonces, varias reformas legales y medidas del gobierno han intentado prevenir el abuso del poder policial. Así, por ejemplo, PACE exige actualmente a los agentes policiales hacer un registro escrito del ejercicio del poder incluyendo las razones que llevaron al policía a decidir la realización del control, la identidad del agente policial que realiza el procedimiento, las circunstancias y varias características de la persona sujeta a control, como su edad, sexo y etnia. El nombre de la persona puede no estar contemplado en el reporte si la policía no cuenta con dicha información. No existe obligación alguna de responder a las preguntas de la policía. Por último, la persona puede exigir una copia del reporte.

Adicionalmente, en un esfuerzo por controlar la discrecionalidad policial para determinar aquello que es considerado como sospechoso, el Código de Buenas Prácticas que regula la materia establece que las sospechas no pueden estar basadas en factores personales si no existen antecedentes de inteligencia confiables o algún comportamiento específico de la persona. El Código establece además que la raza de una persona, su edad, apariencia o el hecho de tener antecedentes penales, no pueden ser usados en sí mismas o en conjunto como razones para controlar. Por último agrega que la sospecha razonable no puede estar basada en generalizaciones o imágenes estereotipadas de que ciertos grupos o categorías de personas sean más propensos a involucrarse en actividades criminales ${ }^{69}$.

Por otra parte, existen diferentes vías de denuncias contra actuaciones policiales incorrectas. Junto con acciones civiles y penales en las cortes, la víctima de abuso policial puede hacer una denuncia ante una comisión independiente cuya función es supervigilar la actuación policial (IPCC). La comisión puede sancionar disciplinariamente al policía o dar lugar a una querella criminal. Además, la policía está sujeta a la legislación de antidiscriminación la cual es monitoreada por una Comisión de Igualdad y Derechos Humanos que cuenta con una serie de facultades de control. Por último, es importante destacar que abundante información se encuentra disponible sobre el ejercicio de la labor policial, especialmente en relación al trato que reciben grupos minoritarios. Así, la Ley de Justicia Criminal de $1991^{70}$ exige a la policía publicaciones anuales con estadísticas del origen étnico de las personas sujetas a control y las personas involucradas en causas criminales. Otra importante fuente de información es el Plan de Acción del Ministerio del Interior que desde 1999 se ha enfocado en la realización de investigaciones sobre el uso del SAS.

\footnotetext{
${ }^{67}$ SCARMAN, Lord, The Brixton Disorders 10-12 April 1981: Report of an Inquiry, Londres: O.B.E. Home Office 1981, p. 8.

${ }^{68}$ REINER, Robert, The Politics of the Police, Oxford: Oxford University Press, Cuarta Edición, 2010 , p. 205.

${ }^{69}$ HOME OFFICE, Code of Practice for the Exercise by Police Officers of Statutory Powers of Stop and Search, Code A, Londres: Home Office, 2005.

${ }^{70}$ Sección 95 de la Ley de Justicia Criminal de 1991.
} 
IRARRÁZABAL, Paz. "Igualdad en las calles en Chile: el caso del control de identidad".

\subsection{El uso del stop and search.}

En el Reino Unido reportes oficiales e investigaciones desarrolladas desde la academia reconocen como no controvertido el hecho que la policía en el ejercicio de sus funciones, se dedica de una forma desproporcionada a la vigilancia y control de hombres jóvenes pertenecientes a grupos minoritarios ${ }^{71}$. En efecto, como demuestran las abundantes estadísticas disponibles, las minorías étnicas son desproporcionadamente sometidas a SAS en comparación con la "población general" o la "población residente" en una determinada zona $^{72}$. Las Estadísticas sobre Raza y Sistema Penal publicada en conformidad a la Ley de Justicia Criminal muestran como en 2011/12 la probabilidad de ser sometida a SAS de una persona que se identificara a sí misma como perteneciente a la comunidad negra era seis veces más que una persona de raza blanca. Por su parte, la probabilidad de que una persona perteneciente a grupos asiáticos o mixtos fuera sometida a control era dos veces mayor que una persona blanca ${ }^{73}$.

Siendo un hecho de la causa la excesiva vigilancia de grupos minoritarios, existe un intenso debate en relación con las razones que explicarían esta desproporción en el uso del SAS. Algunos autores argumentan que existe un problema de selectividad que refleja el actuar discriminatorio de la policía. Otros autores disputan dicha afirmación argumentando que la desproporción dice relación con la presencia de ciertas personas en el espacio público y la diferencia en la propensión a cometer crímenes de ciertos grupos de personas. Revisaré estas dos posiciones a continuación.

\subsubsection{Desproporción no imputable a la policía.}

Investigaciones del gobierno y de la academia han señalado que la desproporción que se constata en las estadísticas sobre el uso del SAS no puede ser imputable a un actuar discriminatorio de la policía ${ }^{74}$. Desde esta posición se ha criticado que la comparación sobre desproporcionalidad se efectúe en relación con la población total o residente en una determinada área de la ciudad, argumentándose que el grupo de personas sujeta a control policial se limita a aquellos que usan el espacio público. De acuerdo a P.A.J. Waddington y otros, diferentes secciones de la población usan con distinta intensidad las calles y parques; así, por ejemplo, las personas de más edad y las mujeres pueden sentirse más vulnerables al crimen callejero desincentivando su presencia en estos espacios. Estos autores defienden, por tanto, que las estadísticas sobre el uso de SAS deben ser comparadas no con la composición racial de la población residente sino que con la composición de aquellos disponibles para ser sujetos de control dada su presencia en el espacio público ${ }^{75}$.

De acuerdo a las investigaciones del gobierno, cuando la comparación es hecha en relación con la composición racial de las personas disponibles en áreas de alto crimen y altos niveles

\footnotetext{
${ }^{71}$ REINER, The Politics, cit. nota ${ }^{\circ} 68$, p. 164.

72 BOWLING, Benjamin y PHILLIPS, Coretta, "Disproportionate and Discriminatory: Reviewing the Evidence on Police Stop and Search", The Modern Law Review 70 (2007), pp. 936 - 961, p. 944.

${ }^{73}$ MINISTRY OF JUSTICE, Statistics on Race and the Criminal Justice System 2012, pp. 11 y 12.

${ }^{74}$ WADDINGTON, P.A.J., STENSON, Kevin y DON, David, "In Proportion. Race, and Police Stop and Search”, British Journal of Criminology, 44 (2004), pp. 889 - 914.

${ }^{75}$ WADDINGTON/STENSON/DON, "In proportion", cit. nota $\mathrm{n}^{\circ} 74$, p. 890.
} 
Polít. crim. Vol. 10, № 19 (Julio 2015), Art. 8, pp. 234-265.

[http://www.politicacriminal.cl/Vol_10/n_19/Vol10N19A8.pdf]

de SAS, las minorías étnicas no están sobre representadas en las estadísticas, demostrando de esta forma la inexistencia del extendido prejuicio por parte de la policía contra personas de grupos minoritarios ${ }^{76}$.

En segundo lugar, se ha señalado que la proporción de personas miembros de minorías raciales sometidas a SAS se correspondería con su involucramiento en crímenes y desordenes $^{77}$. Así por ejemplo, si se considera los números de personas arrestadas en procedimientos de SAS no existe desproporción entre los distintos grupos raciales. Esto demostraría que las sospechas que llevaron a la policía a realizar SAS estaban bien fundadas. Por otra parte las estadísticas de arrestos en general (no solo los que son el resultado de un SAS) han sido usadas para demostrar que efectivamente hay una mayor proporción de hombres de grupos minoritarios involucrados en el sistema penal como perpetradores de ofensas y, por tanto, su mayor proporción en las estadísticas de SAS es una consecuencia lógica ${ }^{78}$. Así, por ejemplo, se explicaría la baja representación de las mujeres en las estadísticas de arresto y SAS, toda vez que la participación de las mujeres en crímenes es menor que la de hombres.

En consecuencia, para aquellos que sostienen esta línea de argumento, la mayor representación de ciertas minorías en las estadísticas del SAS se explica por su mayor presencia en los espacios públicos y por su mayor involucramiento en actividades criminales, no por conductas discriminatorias de la policía.

\subsubsection{Discriminación policial.}

Otros autores señalan que la desproporción en el uso del SAS respecto a minorías étnicas se debe a discriminación policial. En primer lugar, la policía cuenta con un ámbito de discrecionalidad para decidir dónde y cuándo ejercer su poder de $\mathrm{SAS}^{79}$. De hecho la concentración de controles en ciertas áreas geográficas y respecto de ciertos grupos de la población es el resultado de políticas policiales y decisiones estratégicas sobre el uso de sus recursos. Este grupo de autores señala que la policía en la práctica decide usar SAS en lugares con alta presencia de comunidades minoritarias y, en consecuencia, dichas comunidades están más expuestas a control. Así, de acuerdo a la fuerte crítica desarrollada por Lee Bridge, el argumento de que la desproporción en el uso de SAS respecto de minorías está fuera del control policial es similar a sostener que la esclavitud no fue una institución racista, toda vez que el desproporcionado impacto en la población negra fue solo

\footnotetext{
${ }^{76}$ MILLER, Joel, Profiling Populations Available for Stop and Searches, Londres: Police Research Series. Paper 131, Policing and Reducing Crime Unit Research, Development and Statistics Directorate, Home Office, 2001, p. vi. Ver también WADDINGTON/STENSON/DON, "In proportion", cit. nota ${ }^{\circ}$ 74, quienes presentan investigaciones que muestran igual tendencia.

${ }^{77}$ HOME OFFICE, Race and the Criminal Justice System 2005: A Publication Under Section 95 of the Criminal Justice Act 1991, Londres: Home Office Research and Statistics Directorate, 2006, Tabla 4.430.

${ }^{78}$ WADDINGTON, P.A.J., Policing Citizens, Londres: Routledge, 1998.

${ }^{79}$ BOWLING/PHILLIPS, "Disproportionate", cit. nota n ${ }^{\circ} 72$, p. 946, y EQUALITY AND HUMAN RIGHTS COMMISSION, Stop and Think: A Critical Review of the Use of Stop and Search Powers in England and Wales, Londres: Equality and Human Rights Commission, 2010, p. 52 en http://www.equalityhumanrights.com/sites/default/files/documents/raceinbritain/ehrc_stop_and_search_report .pdf [visitado el 28.09.14].
} 
el producto de la constitución racial de la población disponible a ser capturada y esclavizada en África en un determinado momento histórico ${ }^{80}$.

En segundo lugar, los críticos del uso del SAS han señalado que la forma en que el poder es usado en cada caso concreto también depende de la discrecionalidad policial. La actitud del oficial al aproximarse a un individuo para someterlo a control determina en gran medida la naturaleza del encuentro; así como también el nivel de intrusividad del registro puede dar lugar a distintos resultados ${ }^{81}$. Las decisiones de los policías en estas materias tiene un impacto directo en las tasas de arresto, socavando el argumento sobre la diferencia en el involucramiento criminal de ciertos grupos de personas. De hecho, las cifras de arrestos producidos en procedimientos de SAS son, en parte, el resultado de confrontaciones entre la policía y personas que se resisten al control ${ }^{82}$. Los arrestos pueden ser también el resultado del incumplimiento de lo que se ha denominado el "test de actitud", es decir que la persona sometida a control se haya mostrado irrespetuosa o insuficientemente deferente con el oficial ${ }^{83}$. De acuerdo a Robert Reiner, este tipo de arrestos son el resultado de un imperativo de la cultura policial que exige que la policía parezca tener siempre el control de la situación. Esto explicaría, por ejemplo, que de acuerdo a las investigaciones realizadas por diferentes autores, la presencia de testigos aumente las posibilidades de ser arrestado ${ }^{84}$.

Por último, el uso de prejuicios y estereotipos por parte de la policía es inevitable cuando la ley exige constatar evidencias de actuar sospechoso en los individuos para someterlos a control. Al decidir aquello que resulta sospechoso la policía cuenta con altos niveles de discreción. El problema aquí es cómo puede definirse lo que es sospechoso sin acudir a preconcepciones sobre comunidades consideradas más propensas a la criminalidad. Benjamin Bowling y Coretta Phillips han señalado que los patrones de desproporcionalidad en el uso de SAS son consistentes con los patrones de selectividad penal basados en estereotipos y una tendencia cultural a sospechar de las personas de raza negra ${ }^{85}$. Además, estos autores señalan la existencia de abundantes investigaciones que han expuesto prejuicios raciales en las fuerzas policiales ${ }^{86}$. Las investigaciones han encontrado que ciertos estereotipos son comúnmente usados por los oficiales de policía para clasificar a las personas en relación con su origen étnico, como por ejemplo, los musulmanes son consideraros como astutos, mentirosos e inmigrantes ilegales, y después del 2001 son también vistos como violentos y potenciales terroristas. Por su parte, personas de raza negra son asociados a delitos violentos y abuso de drogas ${ }^{87}$.

Paul Quinton es un criminólogo que realizó una exhaustiva investigación sobre las dificultades de evitar el uso de estereotipos en las decisiones sobre conductas sospechosas

\footnotetext{
${ }^{80}$ BRIDGES, Lee, "Race, Law and the State", Race \& Class, 43 (2001), pp. 61 - 76, p. 67.

${ }^{81}$ REINER, The Politics, cit. nota n ${ }^{\circ} 68$ y BOWLING/PHILLIPS, "Disproportionate", cit. nota ${ }^{\circ} 72$, p. 951.

${ }^{82}$ BOWLING/PHILLIPS, "Disproportionate", cit. nota $\mathrm{n}^{\circ} 72$, p. 952.

${ }^{83}$ REINER, The Politics, cit. nota ${ }^{\circ} 68$, pp. 164 y 170.

${ }^{84}$ REINER, The Politics, cit. nota ${ }^{\circ} 68, \mathrm{p} .170$.

${ }^{85}$ BOWLING/PHILLIPS, “Disproportionate", cit. nota $n^{\circ} 72$, p. 956.

${ }^{86}$ BOWLING/PHILLIPS, "Disproportionate", cit. nota ${ }^{\circ} 72$, p. 954.

${ }^{87}$ BOWLING, Benjamin y PHILLIPS, Coretta, "Policing Ethnic Minority Communities", en: NEWBORN Tim (Ed.), Handbook of Policing, Londres: Willan Publishing, 2003, p. 529.
} 
Polít. crim. Vol. 10, № 19 (Julio 2015), Art. 8, pp. 234-265.

[http://www.politicacriminal.cl/Vol_10/n_19/Vol10N19A8.pdf]

que la policía debe realizar cotidianamente ${ }^{88}$. En su estudio señaló que los oficiales entrevistados tuvieron serias dificultades para describir qué significaba en la práctica "sospecha razonable", mostrando importantes diferencias sobre los factores que eran considerados para controlar a una persona. Así por ejemplo se señalaron los siguientes factores: mirar fijamente al policía; no hacer contacto visual; jóvenes, especialmente si andan en grupos o se encuentran alrededor de autos; caminar sin un destino claro; ropa deportiva, viseras, polerones con capucha; actos de desorden tales como beber en la vía pública; actos que tienen como propósito molestar o desafiar a la policía (como hacer sonidos de cerdos); conocimiento previo de ciertas personas (los "regulares"); evitar o ponerse nervioso frente a la policía toda vez que "quien nada hace nada teme". La raza y la nacionalidad también aparecen señaladas como factores relevantes a considerar, ya que de acuerdo a la policía distintas razas tienen distintas propensión al crimen y la violencia. El autor termina concluyendo que en la práctica policial los factores de sospecha no son objetivos sino que se basan en generalización y estereotipos sobre los distintos grupos sociales.

\subsubsection{Desigualdades estructurales y el impacto en la función policial.}

En la discusión en el Reino Unido sobre la justicia en el uso del SAS se han planteado también argumentos que apuntan a los problemas sistemáticos que constituyen el contexto en que la función policial es ejercida y que repercuten inevitablemente en los resultados de la labor policial, independientemente de las intenciones de los oficiales. Así, por ejemplo, si bien Waddington niega el uso incorrecto del poder por parte de los oficiales de policía, reconoce como las desigualdades estructurales de la sociedad repercuten en su uso. Señala que las prácticas cotidianas de la policía reflejan e incluso refuerzan las profundas divisiones y desigualdades que influencian el uso que los ciudadanos dan al espacio público $^{89}$.

\section{a) Desigualdades estructurales.}

Un primer problema social que produce desproporcionalidad en el uso de SAS dice relación con la existencia de racismo y discriminación en la sociedad en general. Este contexto afecta las decisiones de los oficiales de policía independientemente de sus motivaciones personales. Los policías comparten los valores de la sociedad a la que pertenecen ${ }^{90}$. Adicionalmente, la discriminación puede ser consecuencia de lo que ha sido denominado "discriminación transmitida" ". Esto es, los prejuicios de la sociedad civil son comunicados a la policía, por ejemplo, cuando los estereotipos de los ciudadanos afectan la descripción de los supuestos infractores de la ley. De acuerdo a diversas investigaciones, un porcentaje importante de controles efectuados a hombres negros inocentes fueron resultado del señalamiento que víctimas de delitos habían hecho de dichas personas ${ }^{92}$.

\footnotetext{
${ }^{88}$ QUINTON, Paul, "The Formation of Suspicions: Police Stop and Search Practices in England and Wales", Policing and Society: An International Journal of Research and Policy, 21, 4 (2011), pp. 357 - 368.

${ }^{89}$ WADDINGTON/STENSON/DON, "In proportion", cit. nota n ${ }^{\circ} 74$, p. 910.

${ }^{90}$ REINER, The Politics, cit. nota $\mathrm{n}^{\circ}$ 68, p.130.

${ }^{91}$ REINER, The Politics, cit. nota $\mathrm{n}^{\circ}$ 68, p.161.

${ }^{92}$ REINER, The Politics, cit. nota ${ }^{\circ}$ 68, p. 167.
} 
IRARRÁZABAL, Paz. "Igualdad en las calles en Chile: el caso del control de identidad".

Un segundo problema estructural dice relación con la selectividad de la persecución penal en general. En palabras de Reiner, en la práctica el hecho de ser joven, hombre, negro, desempleado y contar con escasos recursos repercute directamente en la mayor posibilidad de ser parado, registrado, arrestado, detenido, imputado y condenado ${ }^{93}$. Excede el propósito de este artículo hacerse cargo de la compleja discusión sobre la selectividad del sistema penal en relación con la persecución de ciertas infracciones y ciertos infractores, sin embrago, es importante tener presente que los crímenes e individuos sujetos al control policial a través del SAS corresponden a una proporción pequeña de la criminalidad total y que los crímenes y las personas controladas y perseguidas criminalmente reflejan mayormente las presiones políticas y expectativas sociales sobre cómo la policía debiera ejercer su función. Las presiones sociales en la policía para resguardar una específica concepción de orden es observado por Waddington, quien señala que las decisiones para destinar recursos policiales al espacio público, en vez de, por ejemplo, enfocarse en menos visibles infracciones cometidas por grupos sociales más aventajados, responden a particulares políticas de control de crimen ${ }^{94}$.

En tercer lugar, el hecho que el SAS afecte a aquellos que se encuentran en los espacios públicos es también un problema de desigualdades estructurales en nuestras sociedades. La pregunta que debe plantearse aquí es por qué la población disponible para el control policial tiene un perfil racial diferente que el resto de la población residente. De acuerdo a Bowling y Phillips, la disponibilidad de ciertas personas depende de factores estructurales como exclusión de educación formal, vivienda, mercado laboral o el tipo de trabajo que se realice, si se trabaja en turnos nocturnos o si se es excluido del uso de espacios privados. En la realidad del Reino Unido cada uno de estos factores de exclusión afecta mayoritariamente a minorías raciales ${ }^{95}$.

\section{b) Impacto negativo en el individuo y la comunidad.}

El uso desproporcionado del poder de SAS con relación a minorías étnicas, sea causada o no por discriminación policial, genera serias consecuencias sociales en contextos de gran desigualdad. En el Reino Unido las minorías son efectivamente sujetas a mayor control policial y esto inevitablemente repercute en la experiencia de estas personas en el espacio público. El impacto negativo del SAS debe ser evaluado desde la experiencia de los individuos y también en relación a la repercusión en la comunidad en general.

La experiencia individual de humillación que implica ser sometido a control policial en la calle debe ser entendida en relación con los estereotipos que se aparejan al ejercicio de dicho control. A través del uso de SAS la policía comunica mensajes de exclusión o inclusión $^{96}$, de respetabilidad del individuo o la falta de dicho atributo ${ }^{97}$. Esta expresiva

\footnotetext{
${ }^{93}$ REINER, The Politics, cit. nota n ${ }^{\circ} 68$, p. 165.

${ }^{94}$ WADDINGTON/STENSON/DON, "In proportion”, cit. nota ${ }^{\circ} 74$, p. 910.

${ }^{95}$ HALLSWORTH, Simon, "Racial Targeting and Social Control: Looking Behind the Police", Critical Criminology, 14 (2006), pp. 293 - 311.

${ }^{96}$ BRADFORD, Ben, "Policing and Social Identity: Procedural Justice, Inclusion and Cooperation between Police and Public", Policing \& Society 24, 1 (2014), pp. 22- 43.

${ }^{97}$ WADDINGTON, Policing, cit. nota ${ }^{\circ} 78$, pp. 62 y 63.
} 
Polít. crim. Vol. 10, № 19 (Julio 2015), Art. 8, pp. 234-265.

[http://www.politicacriminal.cl/Vol_10/n_19/Vol10N19A8.pdf]

consecuencia que se sigue de la actuación policial es inevitable al ser esta la institución encargada de controlar la criminalidad, y cuando la misma regulación del SAS implica que alguna evidencia de actuar sospechoso debe haber sido identificada en el sujeto controlado. En otras palabras, aquellos controlados por la policía han fracasado en mostrar los signos normales de respetabilidad y la consecuente interacción con la policía los marca como sospechosos.

La sensación de ser estereotipados al ser sometido al control policial es ilustrada por una investigación desarrollada por Apla Parmar en relación a un poder especial de SAS en caso de sospecha de acciones vinculadas a actos terroristas ${ }^{98}$. De acuerdo a dicha investigación, las personas sometidas a SAS sentían que habían sido controladas porque eran visiblemente asiáticos, negros o "parecían musulmanes", lo que las marcaba como terroristas. Estos reclamos no estaban presentes en las declaraciones de ciudadanos blancos sometidos a igual control, quienes por lo general tenían una visión positiva de la actuación policial a su respecto. Parmar agrega que algunos de los entrevistados de raza blanca señalaron que ellos tenían la impresión de que habían sido controlados por la policía para "balancear los números" y de esta forma poder justificar que no solo controlaban a musulmanes.

La investigación de Parmar muestra que el contexto social de desigualdad y prejuicios impacta en cómo sea interpretada la actuación policial. En contextos de desigualdad es difícil cuestionar la percepción de grupos minoritarios de haber sido objeto de control debido únicamente a su identidad. La convicción de haber sido tratado injustamente por la policía no solo daña la autoestima del individuo sujeto a control sino que también crea resentimiento y recelos hacia la policía. En efecto, en el Reino Unido las investigaciones y encuestas muestran una relación directa entre las experiencias de haber sido sometido a SAS y un antagonismo y desconfianza en la policía ${ }^{99}$. Esta desconfianza entre el individuo y la policía impactan a la comunidad en general a la que pertenece dicho sujeto. La percepción de haber sido sometido a control debido a una específica identidad repercutirá en el resto de dicha comunidad que comparte igual identidad ${ }^{100}$. La repetida experiencia de saber que personas como tú han sido controladas crea lo que se denomina "experiencia vicaria"101.

El impacto negativo que el uso del SAS tiene en los grupos minoritarios ha sido una constante preocupación de la discusión en el Reino Unido ${ }^{102}$. Esta preocupación dice relación con las experiencias de desórdenes violentos que fueron en parte consecuencia de resentimiento de grupos desaventajados hacia la policía. Sin embargo, no es solo la amenaza de desórdenes públicos lo que ha causado preocupación sino también el impacto

\footnotetext{
${ }^{98}$ PARMAR, Alpa, "Stop and Search in London: Counter- Terrorist or Counter-Productive?", Policing \& Society, 21 (2011), pp. 369 - 382, p. 375.

${ }^{99}$ WADDINGTON/STENSON/DON, "In proportion”, cit. nota ${ }^{\circ}$ 74, p. 892; MILLER, Joel, BLAND Nick y QUINTON, Paul, The Impact of Stops and Searches on Crime and the Community, Londres: Home Office, 2000, y MILLER, Profiling, cit. nota $\mathrm{n}^{\circ} 76$, pp. vi, viii y 87.

${ }^{100}$ PARMAR, "Stop", cit. nota ${ }^{\circ}$ 98, p. 376.

101 ROSENBAUM, Dennis et al., "Attitudes toward the Police: the Effects of Direct and Vicarious Experience", Police Quarterly, 8 (2005), pp. 343 - 365.

102 DELSOL/SHINER, "Regulation", cit. nota n 66, p. 244, BOWLING/PHILLIPS, "Disproportionate", cit. nota $\mathrm{n}^{\circ} 72$, p. 959.
} 
IRARRÁZABAL, Paz. "Igualdad en las calles en Chile: el caso del control de identidad".

en la legitimidad de la policía. La confianza en la institución es fundamental para el nivel de legitimidad de esta y es un factor determinante de la cooperación ciudadana que resulta crucial para la efectividad de la labor policial ${ }^{103}$.

En conclusión, la percepción de injusticia en el uso del poder de SAS puede ser difícil de evitar en contextos de desigualdad estructural. La experiencia cotidiana de ser tratado de manera injusta por la policía tiene serias repercusiones en el individuo, la comunidad a la que pertenece y en último término en la legitimidad de la policía.

\subsubsection{Una evaluación final.}

El SAS implica serias amenazas para los miembros de grupos desaventajados y para la relación entre estos grupos y la policía. Sin embargo, aún queda por evaluar si dicho poder puede ser justificado al estar destinado a resguardar un bien público mayor. En efecto, la razón de ser del poder policial es prevenir la comisión de delitos, y por tanto, la efectividad en lograr dicho objetivo puede justificar algún costo social asociado al ejercicio del poder. En esta línea de argumentación, el uso desproporcionado del SAS requiere ser regulado pero el poder en sí mismo puede ser imprescindible para garantizar la paz y seguridad ${ }^{104}$.

De igual forma que la pregunta por la propensión de ciertos grupos a la comisión de crímenes, la pregunta por la efectividad del SAS en la prevención de la criminalidad en las calles resulta compleja. En el Reino Unido se ha argumentado que la baja tasa de arrestos en procedimientos de SAS (solo un $9 \%$ de las personas sometidas a SAS de conformidad a PACE en $2011 / 2012^{105}$ ) demostraría la inefectividad del poder policial. La mayoría de las personas controladas, el $90 \%$, resultan ser inocente de acuerdo a las estadísticas oficiales. Además, como ya fuera mencionado, se ha argumentado que parte importante de los arrestos que suceden a un SAS son el resultado de la resistencia de la persona controlada hacia la actuación policial. Sin embargo, algunos autores han señalado que SAS sí contribuiría a detectar la posesión de ciertos objetos prohibidos como armas y marihuana $^{106}$. También se ha señalado el posible efecto disuasivo a pesar de que éste sea un hecho considerado por los académicos como difícil de probar ${ }^{107}$. Reportes oficiales e investigaciones provenientes del gobierno muestran resultados no concluyentes sobre el rol del SAS en la prevención de crímenes, habiéndose señalado la "poca evidencia seria" que existiría en estas materias ${ }^{108}$.

Debido a la falta de evidencia sobre la efectividad previniendo la criminalidad del SAS es que autores como Bowling y Phillips han abogado por la revisión de la institución. De

\footnotetext{
${ }^{103}$ BRADFORD, "Policing", cit. nota n 96, p. 23. Ver también BOWLING/PHILLIPS, "Disproportionate", cit. nota $\mathrm{n}^{\circ} 72$, p. 939.

${ }^{104}$ LEA, John, "The Macpherson Report and the Question of Institutional Racism", The Howard Journal, 39, 3 (2000), pp. 219 - 233, p. 228.

105 HOME OFFICE, Police Powers and Procedures England and Wales 2011/12 en: https://www.gov.uk/government/publications/police-powers-and-procedures-in-england-and-wales201112/police-powers-and-procedures-in-england-and-wales-2011-12 [visitado el 26.10. 14].

${ }^{106}$ DELSOL/SHINER, "Regulation", cit. nota n ${ }^{\circ} 66$, p. 243 y STRICKLAND, Stop, cit. nota n ${ }^{\circ} 63$, p. 13.

${ }^{107}$ STRICKLAND, Stop, cit. nota n ${ }^{\circ} 63$, p.13.

${ }^{108}$ MILLER, Profiling, cit. nota ${ }^{\circ} 76$, pp. v-vi.
} 
Polít. crim. Vol. 10, № 19 (Julio 2015), Art. 8, pp. 234-265.

[http://www.politicacriminal.cl/Vol_10/n_19/Vol10N19A8.pdf]

acuerdo a estos autores el uso de este poder tiene enorme impacto en la comunidad, afectando a ciudadanos respetuosos del derecho, deslegitimando a la policía, aumentado la confrontación de la policía con la ciudadanía con la potencialidad de desatar desórdenes públicos, y contribuyendo a un desproporcionado arrastre de jóvenes negros al sistema criminal $^{109}$.

Profundizando la crítica, autores como Lea han argumentado que la falta de correlación entre la prevención del crimen y el uso del SAS sí se explicaría si se atiende al verdadero rol que siempre ha tenido dicho poder, que es controlar a las clases peligrosas, conformada por pobres, desempleados, y otros grupos marginados, disciplinando su presencia en el espacio público. De acuerdo a esta aproximación, la excesiva representación de jóvenes negros en las estadísticas del SAS es consecuencia de la discriminación racial existente que empuja desproporcionadamente a este grupo a la clase marginal. La evidencia que requiere la policía para el ejercicio de su poder dice menos relación con comportamientos sospechosos relacionados a la comisión de un delito que con indicadores que muestran la pertenencia a clases desaventajadas ${ }^{110}$.

\section{Justicia en el espacio público y control de identidad.}

El control de identidad en Chile puede plantear serios problemas para la justicia social en el espacio público. Con el objeto de explorar estos problemas y debido a la falta de información respecto a cómo ha sido ejercido este poder es que he recurrido a la discusión suscitada en el Reino Unido sobre el uso de una facultad policial similar. A pesar de los diferentes contextos en que fueron creadas estas facultades y las marcadas diferencias en su actual regulación, con ambas se buscó limitar y racionalizar los poderes preventivos de policía que existían con anterioridad cuyo objetivo expreso era remover del espacio público personas indeseadas. En cambio, el control de identidad y SAS exigen actualmente al agente policial actuar cuando existan indicios razonables para sospechar que se ha cometido un acto ilícito específico, dejando de lado cualquier consideración sobre las características personales o antecedentes del individuo.

A pesar de estos esfuerzos, tanto en Chile como en el Reino Unido se han suscitado reclamos por abuso policial en el ejercicio de las nuevas facultades. En Chile cerca de dos millones de controles de identidad se realizaron en el 2014 pero existe una preocupante falta de información sobre las circunstancias y el perfil de las personas sujetas a dichos controles. Esta falta de datos unida a inadecuados mecanismos de control del actuar policial, implican una seria amenaza para el respeto de los derechos de las personas en las calles. Las pocas pistas que han sido revisadas en este artículo sobre el uso del control de identidad más la experiencia de Reino Unido que ha sido expuesta arriba pueden alertarnos sobre los riesgos que para la libertad e igual respeto de los ciudadanos implican estos poderes policiales preventivos.

\footnotetext{
${ }^{109}$ BOWLING/PHILLIPS, "Disproportionate”, cit. nota $\mathrm{n}^{\circ} 72$, p. 959.

${ }^{110}$ LEA, "The Macpherson", cit. nota n' 104, p. 230.
} 
IRARRÁZABAL, Paz. "Igualdad en las calles en Chile: el caso del control de identidad".

En esta última parte concluiré con una reflexión acerca de las consecuencias que para la justicia social en el espacio público puede implicar la existencia del control de identidad en el contexto chileno. Algunos factores que constituyen este contexto en que se ejerce el control policial son los siguientes: (1) una aún débil democracia que implica insuficientes controles institucionales y desde la sociedad civil en la protección de derechos; (2) preponderancia de un determinado discurso de "ley y orden", que fuera señalado más arriba; (3) desigualdad socioeconómica que se expresa en el espacio urbano en una marcada segregación y privatización de los espacios ${ }^{111}$ y (4) aumento de la diversidad en las ciudades. Una causa importante de dicha diversidad ha sido el sostenido arribo de migrantes rurales e inmigrantes principalmente de nuestros países vecinos ${ }^{112}$. En este contexto la posibilidad de un desproporcionado impacto de la facultad policial en ciertos grupos desaventajados, como queda en evidencia en el caso inglés, debe ser objeto de especial preocupación.

Esta reflexión puede ser guiada por una aproximación que atiende al impacto que la facultad policial tiene en la libertad de dichas personas, o desde una segunda aproximación que atiende al efecto en la igualdad, no sólo en relación a sus exigencias distributivas sino que también en cuanto al tipo de relaciones sociales a que da lugar o refuerza este tipo de instituciones.

\subsection{El derecho a caminar por las calles.}

Como punto de partida, no es mayormente controvertido afirmar que el control de identidad implica una interferencia con la libertad personal y de movimiento. Ahora, en condiciones de ejercicio adecuado de la facultad policial es posible argumentar sobre su legitimidad en la medida que permite proveer protección a los derechos de todos, resguardando el orden público y la seguridad. En efecto, estos argumentos fueron sostenidos en el debate parlamentario en Chile más arriba señalado.

Sin embargo, este argumento sobre la libertad y la existencia de un conflicto de derechos es insuficiente para dar cuenta de los problemas de justicia social cuando se considera el contexto en el cual la facultad policial es ejercida. Un primer factor contextual a considerar en Chile dice relación con la protección de la propiedad privada y la privatización de los espacios públicos. La libertad de aquellas personas que cuentan con limitadas opciones de estar en espacios privados se ve espacialmente afectada por la regulación del uso de los espacios públicos. En esta situación se encuentran, entre otros, los jóvenes, especialmente los de clases sociales más bajas; las personas que usan el transporte público; aquellos que carecen de acceso a parques o lugares de esparcimiento que se encuentran en dominios privados; las personas que trabajan en la calle, como vendedores ambulantes, y trabajadores

111 SABATINI, Francisco, CÁCERES, Gonzalo y CERDA, Jorge, "Segregación Residencial en las Principales Ciudades Chilenas: Tendencias de las Tres Últimas Décadas y Posibles Cursos de Acción" Revista Latinoamericana de Estudios Urbanos Regionales 27 (2001), en: <http://www.scielo.cl/scielo.php?script=sci_arttext\&pid=S0250-71612001008200002> [visitado el 26.11.14]

${ }^{112}$ En 1996 la mitad de la población indígena en Chile vivía en las ciudades. De acuerdo a la CASEN del 2011 esta cifra aumentó a 73, 4\%. Por otra parte, la inmigración en Chile ha aumentado significativamente desde 1990 y entre 2002 y 2012 el número de extranjeros viviendo en Chile creció un 84\%. CENTRO DE DERECHOS HUMANOS DE LA UNIVERSIDAD DIEGO PORTALES, Informe, cit. nota n 40, p. 128. 
Polít. crim. Vol. 10, № 19 (Julio 2015), Art. 8, pp. 234-265.

[http://www.politicacriminal.cl/Vol_10/n_19/Vol10N19A8.pdf]

sexuales; y los inmigrantes en búsqueda de trabajos temporales. Personas como estas son expuestas de manera desproporcionada a ser controladas por la policía. Como ha sido resaltado en la discusión británica, la disponibilidad de ciertos grupos de personas en las calles para ser controladas dice relación directa con condiciones estructurales de igualdad en la sociedad.

El impacto que para la libertad de personas pertenecientes a grupos desaventajados tiene la protección de la propiedad privada y el control del orden público ha sido discutido por Jeremy Waldron ${ }^{113}$ en relación con la dictación de leyes en Estados Unidos que fueron conocidas como "anti-homeless laws", al regular acciones como acostarse u orinar en las calles y plazas. De acuerdo a Waldron, estas leyes que regulan comportamientos en el espacio público afectan seriamente la libertad de aquellos excluidos de los espacios privados. En el caso de las personas sin hogar estas restricciones suponen prohibiciones absolutas. En sus palabras, "como los espacios públicos y privados constituyen todo el espacio en el que se puede estar, no hay lugar alguno donde estas acciones pueden ser realizadas por la persona sin hogar. Y dado que la libertad de desarrollar una acción concreta requiere de la libertad de poder realizarla en algún lugar, se sigue que la persona sin hogar no tiene libertad para realizarla en lo absoluto" "114. Lo que el caso extremo de las personas sin hogar ilustra es que las regulaciones sobre el espacio público afectan la libertad de forma dispar dependiendo de la posición social de las personas y su posibilidad de acceso y disfrute de espacios privados.

Un segundo factor a considerar en este supuesto conflicto de derechos, se relaciona a las ideas que existen en una comunidad específica acerca de lo que constituye orden público y seguridad que fundamentaría la acción policial. Este tema ha sido discutido desde la geografía urbana por autores que han revindicado el "derecho a la ciudad". Don Mitchell ${ }^{115}$ señala que este derecho implica preguntarse qué tipo de orden promueve una ciudad más justa $^{116}$, cómo regulamos su uso en función a esa idea de orden y cómo la comunidad de forma colectiva debe decidir estas cuestiones evitando que grupos poderosos capturen los espacios urbanos para sus propios intereses. De acuerdo a este autor, la expansión de espacios privatizados y una supuesta idea de orden para garantizar la libertad y seguridad han generado un control excluyente de las ciudades ${ }^{117}$.

La preponderancia en Chile de un discurso de "ley y orden" y la existencia de un pánico moral en relación con ciertos tipos específicos de desorden y criminalidad contribuye a aumentar el control de ciertos sectores más desaventajados de la población. Fue la existencia de este discurso el que provocó una reforma casi bianual del control de identidad en el parlamento, aumentado progresivamente la facultad policial hasta el punto de llegar a asimilarla a la detención por sospecha. En efecto, en la actual regulación del control de

\footnotetext{
${ }^{113}$ WALDRON, Jeremy, "Homelessness and the Issue of Freedom”, UCLA Law Review, 39 (1991-1992), pp. $295-324$.

${ }^{114}$ WALDRON, “Homelessness", cit. nota ${ }^{\circ} 113$, p. 315. Traducción propia.

${ }^{115}$ MITCHELL, Don, The Right to the City: Social Justice and the Right for Public Space, Neva York: The Guilford Press, 2003, p. 147.

${ }^{116}$ MITCHELL, The Right, cit. nota $\mathrm{n}^{\circ} 115$, p. 288.

${ }^{117}$ MITCHELL, The Right, cit. nota ${ }^{\circ} 115$, p. 73.
} 
IRARRÁZABAL, Paz. "Igualdad en las calles en Chile: el caso del control de identidad".

identidad cualquier joven usando capucha o cualquier circunstancia de desorden puede constituir suficiente evidencia para la realización del control. Además este mismo discurso que definió la actual regulación del control de identidad ejerce una presión política que influye en el diseño de políticas policiales y las decisiones cotidianas de Carabineros en las calles. Como fuera señalado en la discusión británica, la preocupación por cierto tipo de ofensas y las exigencias sociales impuestas a la policía dan lugar un muy selectivo control social.

La definición de los espacios privados, la regulación de los espacios públicos, la presencia de ciertos grupos de personas en las calles y las ideas prevalentes sobre orden llevan a cuestionarse sobre la forma en que la libertad y las cargas son distribuidas entre los ciudadanos o en otras palabras, ¿quién tiene el derecho a caminar con libertad por las calles? y ¿quién debe soportar la cargas que resultan del mantenimiento del orden público?

\subsection{Una comunidad de iguales.}

De acuerdo a lo que he venido describiendo en este artículo hoy en día las cargas que implican el mantenimiento del orden son soportadas por grupos de personas que comparten ciertas características que no se vinculan necesariamente a algún comportamiento delictual. Hay ciertos antecedentes para sostener que la mayoría de las personas controladas en Chile, de los casi dos millones de controles de identidad al año, han atraído la atención de la policía no por haber cometido algún crimen sino que por su pertenencia a grupos desaventajados o discriminados y por su disponibilidad en el espacio público. De esta forma, las condiciones estructurales de desigualdad y segregación en Chile son factores habilitantes para un ejercicio discriminatorio de las funciones policiales. En este contexto, el igual respeto y consideración que toda persona merece resulta amenazado.

En primer lugar, se incurre en una distribución desigual de las cargas en el intento de asegurar una específica idea de orden público. Se ha alegado por algunos defensores de la regulación legal que el control de identidad supone un costo social razonable para garantizar la seguridad de todos ${ }^{118}$. Pero según lo más arriba señalado, no todos en Chile asumimos algo de ese costo. Solo ciertos grupos de personas son sometidas al procedimento policial y la mayoría de ellas son controladas por razones que no están bajo su control. Desde una perspectiva igualitaria, la distribución de cargas sociales basada en criterios arbitrarios debe ser rechazada.

En segundo lugar, el control de identidad implica una amenaza a relaciones igualitarias en el espacio público, hiriendo la dignidad e igual respeto de algunos ciudadanos. Esto porque la facultad policial de controlar la identidad cumple un rol estableciendo los márgenes entre la respetabilidad y criminalidad. De esta forma cumple una función creando y reforzando estereotipos y jerarquías sociales en Chile. Sobre este punto me detendré en lo que sigue.

Estructuras institucionales injustas en una sociedad determinan no solo las condiciones materiales de la vida de la personas sino que también definen las relaciones de

\footnotetext{
${ }^{118}$ Ver discusión parlamentaria en 1.1.
} 
Polít. crim. Vol. 10, № 19 (Julio 2015), Art. 8, pp. 234-265.

[http://www.politicacriminal.cl/Vol_10/n_19/Vol10N19A8.pdf]

respetabilidad, poder, autoridad y estatus que permean todos los ámbitos sociales. Iris Marion Young, por ejemplo, ha denunciado las relaciones de estatus y respetabilidad que derivan de nuestro sistema de división del trabajo y participación de las personas en el mercado laboral $^{119}$. Elizabeth Anderson, por su parte, acusa a la segregación urbana de la creación de dichas diferencias entre las personas ${ }^{120}$. Desigualdades estructurales y estereotipos que surgen de éstas se expresan en el espacio público en la forma que las personas son tratadas por otros ciudadanos y agentes del estado. Por ejemplo, la respetabilidad de la que gozan grupos con poder, como los profesionales, que se expresa en particulares formas de vestir, hablar y comportarse, tiene impacto en la forma en que son tratados en el espacio público por otras personas. Mientras que aquellos con otros códigos de conducta y comunicación son considerados como no confiables, teniendo la carga de probar su respetabilidad en encuentros cotidianos.

En contextos de desigualdad estructural, el poder de controlar individuos en las calles que resultan sospechosos para la policía es altamente problemático. Como ha sido señalado más arriba, la determinación de lo "sospechoso" en pasajeros encuentros en el espacio público lleva fácilmente a la utilización de estereotipos sobre criminalidad y respetabilidad en una determinada sociedad. El problema aquí es cómo determinar el tipo de comportamiento específico que puede ser considerado como evidencia para el control, sin recurrir a preconcepciones de cómo un "delincuente" se ve y comporta.

La regulación chilena del control de identidad tiene un problema adicional al facultar el control de aquellos que de acuerdo a la policía escondan su verdadera identidad. Este es un complejo poder que implica vigilar derechamente la apariencia de una persona. Aquí nuevamente preconcepciones sobre cómo lucen personas respetables y respetuosas del derecho entran en juego. Un caso que ilustra las dificultades que plantea la aplicación de esta regulación es el amparo que ordenó la protección de una trabajadora sexual que fuera mencionado en la parte 2. de este artículo. En este caso, Carabineros cuestionó la "verdadera identidad" de la mujer transexual porque de acuerdo a los oficiales ella era en realidad un hombre, tal como aparecía señalado en su cédula de identidad. Debido a que Carabineros consideró que la persona ocultaba su verdadera identidad se entendió facultado para realizar control de identidad.

En este contexto, es difícil pretender que un Carabinero distinga entre comportamientos sospechosos que darían lugar al control de identidad de aquellos factores personales como la apariencia. A fin de cuentas, la facultad policial se ejerce sobre aquellos que resultan sospechosos por la forma que se comportan, pero principalmente por su apariencia e identidad. Ciertamente, los antecedentes que se han presentado en este artículo no permiten dar cuenta de cuál sería el grupo de personas cuya identidad y apariencia los marca como comunidad sospechosa en nuestra sociedad. Información tal como la que permite demostrar la desproporción en el control de miembros de comunidades negras en Reino Unido no existe en Chile. Sin embargo, hay algunos antecedentes que han sido expuestos más arriba

\footnotetext{
${ }^{119}$ YOUNG, Iris Marion, Justice and the Politics of Difference, Princeton: Princeton University Press, 2011.

${ }^{120}$ ANDERSON, Elizabeth, The Imperative of Integration, Princeton: Princeton University Press, 2013.
} 
que permiten vislumbrar cómo los estereotipos y la segregación han influido en el ejercicio del control de identidad.

En primer lugar, el problema social ya señalado de los grupos de personas disponibles en los espacios públicos debe ser tenido en cuenta junto con el problema de la segregación urbana en Chile. Las cortes han reconocido como evidencia de un actuar sospechoso que permitiría la realización de control de identidad el hecho de que una persona sea encontrada en lugares o barrios al que no pertenece. Así, por ejemplo, este criterio puede ser usado fácilmente para sostener que en un barrio de clase alta y con límites fáciles de definir (no solo por estructuras físicas como rejas, sino que también por fronteras simbólicas) la presencia de aquellos que no pertenecen a dicho espacio solo puede ser explicada por intenciones criminales. Al no cuestionar estos presupuestos la policía actúa como un agente activo en los procesos de segregación urbana. Este "rol" policial no solo se ha ejercido en Chile al marcar a aquellos individuos fuera de lugar, sino que también al definir ciertas comunas como peligrosas, lo que contribuye a reforzar estereotipos de criminalidad que afectan a toda una comunidad. En el caso 819-2010, por ejemplo, la corte no cuestionó la explicación de Carabineros en relación al propósito de una visita de una persona a la población La Legua, la que entendió que solo podía deberse a motivos ilícitos.

En segundo lugar, aún más elocuente es el criterio judicial que considera la actitud nerviosa de un individuo hacia la policía como suficiente evidencia de criminalidad. Este criterio casi uniforme de las cortes trae a la luz un aspecto muy sensible y sutil de relaciones desiguales y opresivas. En general, la posibilidad de mirarse a los ojos y mostrarse seguro en las relaciones sociales puede ser determinada de manera importante por la posición social de las personas. Más aún, sentimientos de incomodidad pueden empeorar en encuentros con la policía. Así, por ejemplo, Carabineros representa la autoridad, el uso de la fuerza y, para algunas personas, son la autoridad final en las calles. En otras palabras, la manera en que una persona enfrenta (y desafía) a otros individuos o a Carabineros en las calles depende de su posición y poder social. Al usar estos criterios para decidir acerca de la respetabilidad de una persona, Carabineros y las cortes contribuyen nuevamente en reforzar estereotipos y jerarquías sociales.

Es claro que las preconcepciones existentes en Chile acerca de respetabilidad y criminalidad que impactan la definición de lo sospechoso no solo se relacionan con los limitados criterios recién señalados y que fueran usados por las cortes. Poder identificar la comunidad que ha sido tratada como sospechosa por Carabineros requiere un más completo estudio. Sin embargo, una hipótesis que no resulta riesgosa es que grupos desaventajados marcados por la clase social, etnicidad u orientación sexual se encontrarán representados en cualquier investigación sobre el ejercicio en la práctica del control de identidad. No sería tampoco una sorpresa encontrase con una excesiva vigilancia de ciertos grupos de inmigrantes en Chile. De hecho la amenaza de discriminación policial respecto de inmigrantes no es infundada.

Como fuera señalado, una importante proporción de arrestos declarados ilegales en las cortes penales corresponde a inmigrantes. Además el control de identidad da poder a la policía para solicitar identificación por medio de documentos oficiales, regulación que 
Polít. crim. Vol. 10, № 19 (Julio 2015), Art. 8, pp. 234-265.

[http://www.politicacriminal.cl/Vol_10/n_19/Vol10N19A8.pdf]

puede tener un desproporcionado impacto negativo en este grupo. Finalmente, todo lo señalado resulta consistente con denuncias sobre una creciente discriminación contra inmigrantes latinoamericanos, principalmente contra aquellos a los que se les atribuye rasgos indígenas, quienes han sido culpados por la criminalidad en las calles ${ }^{121}$. Esta nueva dimensión del rol del control de identidad vigilando a los inmigrantes no debe ser desatendida toda vez que, como señala Weber y Bowling, los poderes policiales preventivos frecuentemente constituyen el inicio de proyectos de exclusión de personas que ocupan los márgenes sociales, legales y económicos. Señalan que alrededor del mundo estos poderes se han desarrollado a partir de leyes contra la mendicidad o bien han surgido de estrategias de control de poblaciones colonizadas o subyugadas. En definitiva estos poderes han estado históricamente destinados a controlar a aquellos percibidos como ajenos a la comunidad de respetables ciudadanos ${ }^{122}$.

Al resguardar la respetabilidad y la pertenencia, los policías contribuyen a crear y reforzar desigualdades y estereotipos. Estos efectos negativos difícilmente pueden ser desafiados por grupos sin poder, profundizándose la injusticia social. La amenaza para la igualdad que facultades policiales como el control de identidad supone, no debe ser subestimada.

\section{Conclusiones.}

El control de identidad es una facultad policial para resguardar una específica idea de orden público que implica una restricción de la libertad de las personas en las calles. Esta restricción en contextos de desigualdad afecta de manera desproporcionada a ciertos grupos de personas. Como he argumentado más arriba, afecta arbitrariamente a personas que tienen limitado acceso a los espacios privados y cuya apariencia y comportamiento no se corresponde con ideas imperantes de respetabilidad y confiabilidad. El derecho a caminar por las calles y ser tratados como iguales en los encuentros cotidianos se ve gravemente amenazado por este tipo de facultades preventivas.

La excesiva vigilancia policial de grupos estereotipados no solo afecta los derechos y estatus de los individuos sujetos a control sino que también puede afectar a toda otra persona que entiende compartir igual identidad y, eventualmente, también puede afectar la legitimidad policial. Estas consecuencias negativas que han sido constatadas en el Reino Unido a pesar de los enormes esfuerzos realizados para racionalizar el uso del stop and search, pueden ser aun peor en Chile, donde la falta de controles a la actuación policial resultan patentes. Por todo lo anterior es que es urgente tomar seriamente en consideración las amenazas que el control de identidad supone para los derechos de las personas pertenecientes a grupos más desaventajados y para la construcción de una ciudad justa.

\footnotetext{
${ }^{121}$ DUCCI, María Elena y ROJAS, Loreto, "La Pequeña Lima: Nueva Cara y Vitalidadpara el Centro de Santiago de Chile", Revista Latinoamericana de Estudios Urbanos Regionales 36 (2010), pp. 95-121, p.101, y STEFONI, Carolina, "Migración en Chile" Colección ideas 59 (2005).

${ }^{122}$ WEBER, Leanne y BOWLING, Benjamin, "Stop and Search in Global Context", Policing and Society 21, 4 (2011), pp. 353-256, p. 354.
} 
IRARRÁZABAL, Paz. "Igualdad en las calles en Chile: el caso del control de identidad".

\section{REFERENCIAS BIBLIOGRÁFICAS}

ANDERSON, Elizabeth, The Imperative of Integration, Princeton: Princeton University Press, 2013.

BRADFORD, Ben, "Policing and Social Identity: Procedural Justice, Inclusion and Cooperation between Police and Public", Policing \& Society 24, 1 (2014), pp. 22- 43.

BRIDGES, Lee, "Race, Law and the State", Race \& Class, 43 (2001), pp. 61 - 76.

BOWLING, Benjamin y PHILLIPS, Coretta, "Policing Ethnic Minority Communities", en: NEWBORN, Tim (Ed.), Handbook of Policing, Londres: Willan Publishing, 2003.

, "Disproportionate and Discriminatory: Reviewing the Evidence on Police Stop and Search", The Modern Law Review 70 (2007), pp. 936 - 961.

CENTRO DE DERECHOS HUMANOS DE LA UNIVERSIDAD DIEGO PORTALES. Informe Anual sobre los Derechos Humanos en Chile 2013, en: http://www.derechoshumanos.udp.cl/index.php/informe-anual/repository/funcstartdown/17/

DEFENSORÍA PENAL PÚBLICA, Informe Estadístico Anual 2012, p. 9, en: http://www.dpp.cl/resources/upload/files/documento/9a4c122934927b0ee2c3784299 4663e5.pdf

DELSOL, Rebekah y SHINER, Michael, "Regulation Stop and Search: A Challenge for Police and Community Relations in England and Wales", Critical Criminology, 14 (2006), pp. 241-263.

DUCCI, María Elena y ROJAS, Loreto, "La Pequeña Lima: Nueva Cara y Vitalidad para el Centro de Santiago de Chile", Revista Latinoamericana de Estudios Urbanos Regionales 36 (2010), pp. 95-121.

EQUALITY AND HUMAN RIGHTS COMMISSION, Stop and Think: A Critical Review of the Use of Stop and Search Powers in England and Wales, Londres: Equality and Human Rights Commission, 2010, en http://www.equalityhumanrights.com/sites/default/files/documents/raceinbritain/ehrc stop_and_search_report.pdf.

FUENTES, Claudio, "Violent Police, Passive Citizens", en: PERUZZOTTI, Enrique y SMULOVITZ, Catalina (Eds.), Enforcing the Rule of Law. Social Accountability in the New Latin American Democracies, Pittsburgh: University of Pittsburgh Press, 2006.

FUNDACION SAVIA, Investigación de monitoreo y valoración de la política pública de prevención y atención intehral del VIH y SIDA en población de mujeres ejercen el comercio sexual, 2012, pp. 24-26 en: http://www.fundacionsavia.cl/media/uploads/docs/INVESTIGACION_COMERCIO_SEXUAL_-_2012.pdf

GOFFMAN, Erving, Stigma, Nueva York: Simon and Schuster, 1986.

HALLSWORTH, Simon, "Racial Targeting and Social Control: Looking Behind the Police", Critical Criminology, 14 (2006), pp. 293 - 311.

HOME OFFICE UK, Code of Practice for the Exercise by Police Officers of Statutory Powers of Stop and Search, Code A, Londres: Home Office, 2005.

, Police Powers and Procedures England and Wales 2011/12 en https://www.gov.uk/government/publications/police-powers-and-procedures-in- 
Polít. crim. Vol. 10, № 19 (Julio 2015), Art. 8, pp. 234-265.

[http://www.politicacriminal.cl/Vol_10/n_19/Vol10N19A8.pdf]

england-and-wales-201112/police-powers-and-procedures-in-england-and-wales2011-12.

, Race and the Criminal Justice System 2005: A Publication Under Section 95 of the Criminal Justice Act 1991, Londres: Home Office Research and Statistics Directorate, 2006, Tabla 4.430.

HORVITZ, María Inés, "Seguridad y garantías: derecho penal y procesal penal de prevención de peligros”, Revista de Estudios de la Justicia, 16 (2012), pp. 99-118.

INSTITUTO NACIONAL DE DERECHOS HUMANOS, Reporte Anual 2013 - Programa de Derechos Humanos y Función Policial, en: http://www.camara.cl/pdf.aspx?prmID=20672\&prmTIPO=DOCUMENTOCOMISIO N.

INTERNATIONAL CENTRE FOR PRISON STUDIES: Chile, en http://www.prisonstudies.org/country/chile.

LEA, John, "The Macpherson Report and the Question of Institutional Racism", The Howard Journal, 39, 3 (2000), pp. 219 - 233.

MILLER, Joel, Profiling Populations Available for Stop and Searches, Londres: Police Research Series. Paper 131, Policing and Reducing Crime Unit Research, Development and Statistics Directorate, Home Office, 2001.

MILLER, Joel, BLAND, Nick y QUINTON, Paul, The Impact of Stops and Searches on Crime and the Community, Londres: Home Office, 2000.

MITCHELL, Don, The Right to the City: Social Justice and the Right for Public Space, Neva York: The Guilford Press, 2003.

MOVIMIENTO DE LIBERACIÓN HOMOSEXUAL, XII Informe Anual de Derechos Humanos de la Diversidad Sexual en Chile 2013, en: http://www.movilh.cl/documentacion/XII-Informe-DDHH-de-la-diversidad-sexualMovilh-2013-\%20web-baja.pdf .

O'DONNELL, Guillermo, Democracy, Agency, and the State: Theory with Comparative Intent, Oxford: Oxford University Press, 2010.

PARMAR, Alpa, "Stop and Search in London: Counter- Terrorist or Counter-Productive?", Policing \& Society, 21 (2011), pp. 369 - 382.

QUINTON, Paul, "The Formation of Suspicions: Police Stop and Search Practices in England and Wales", Policing and Society: An International Journal of Research and Policy, 21, 4 (2011), pp. 357 - 368.

REINER, Robert, The Politics of the Police, Oxford: Oxford University Press, Cuarta Edición, 2010.

ROSENBAUM, Dennis et al, "Attitudes toward the Police: the Effects of Direct and Vicarious Experience", Police Quarterly, 8 (2005), pp. 343 - 365.

SABATINI, Francisco, CÁCERES, Gonzalo y CERDA, Jorge, "Segregación Residencial en las Principales Ciudades Chilenas: Tendencias de las Tres Últimas Décadas y Posibles Cursos de Acción" Revista Latinoamericana de Estudios Urbanos Regionales $27 \quad$ (2001), en: $<$ http://www.scielo.cl/scielo.php?script=sci_arttext\&pid=S025071612001008200002> [visistada el 26.11.2014]

SCARMAN, Lord, The Brixton Disorders 10-12 April 1981: Report of an Inquiry, Londres: O.B.E. Home Office 1981.

STEFONI, Carolina, "Migración en Chile” Colección ideas 59 (2005). 
IRARRÁZABAL, Paz. "Igualdad en las calles en Chile: el caso del control de identidad".

STRICKLAND, Pat, Stop and Search, Londres: Home Affairs Section, House of Commons Library, 2014.

WADDINGTON, P.A.J., Policing Citizens, Londres: Routledge, 1998.

WADDINGTON, P.A.J., STENSON, Kevin y DON, David, "In Proportion. Race, and Police Stop and Search", British Journal of Criminology, 44 (2004), pp. 889 - 914.

WALDRON, Jeremy, "Homelessness and the Issue of Freedom", UCLA Law Review, 39 (1991-1992), pp. 295 - 324.

WEBER, Leanne y BOWLING, Benjamin, "Stop and Search in Global Context", Policing and Society 21, 4 (2011), pp. 353- 256

YOUNG, Iris Marion, Justice and the Politics of Difference, Princeton: Princeton University Press, 2011. 